\title{
Quantitative Analysis of the Effects of Intrathylakoid pH and Xanthophyll Cycle Pigments on Chlorophyll $a$ Fluorescence Lifetime Distributions and Intensity in Thylakoids $^{\dagger}$
}

\author{
Adam M. Gilmore, ${ }^{\ddagger}$ Vladimir P. Shinkarev, ${ }^{\S}$ Theodore L. Hazlett," and Govindjee* ${ }^{\star}$ \\ Photobioenergetics Group, Australian National University Research School of Biological Sciences, Canberra, 0200 ACT, \\ Australia, and Departments of Biochemistry and Plant Biology, Center for Biophysics and Computational Biology, and \\ Laboratory for Fluorescence Dynamics, Physics Department, University of Illinois at Urbana-Champaign, \\ Urbana, Illinois 61801
}

Received June 11, 1998; Revised Manuscript Received July 16, 1998

\begin{abstract}
The xanthophyll cycle-dependent dissipation of excitation energy in higher plants is one of the most important regulatory and photoprotective mechanisms in photosynthesis. Using parallel timeresolved and pulse-amplitude modulation fluorometry, we studied the influence of the intrathylakoid $\mathrm{pH}$ and the xanthophyll cycle carotenoids on the PSII chlorophyll (Chl) $a$ fluorescence yield in thylakoids of Arabidopsis, spinach, and barley. Increases in concentrations of dithiothreitol in thylakoids, which have a trans-thylakoid membrane $\mathrm{pH}$ gradient and are known to have decreased conversion of violaxanthin (V) to zeaxanthin (Z), lead to (1) decreases in the fractional intensity of the $\sim 0.5 \mathrm{~ns}$ Chl $a$ fluorescence lifetime $(\tau)$ distribution component and simultaneous increases in a 1.6-1.8 ns fluorescence component and (2) increases in the maximal fluorescence intensity. These effects disappear when the $\mathrm{pH}$ gradient is eliminated by the addition of nigericin. To quantitatively explain these results, we present a new mathematical model that describes the simultaneous effects of the chloroplast trans-thylakoid membrane $\mathrm{pH}$ gradient and xanthophyll cycle pigments on the PSII Chl $a$ fluorescence $\tau$ distributions and intensity. The model assumes that (1) there exists a specific binding site for $\mathrm{Z}$ (or antheraxanthin, A) among or in an inner antenna complex (primarily CP29), (2) this binding site is activated by a low intrathylakoid $\mathrm{pH}$ $(\mathrm{p} K \approx 4.5)$ that increases the affinity for $\mathrm{Z}$ (or $\mathrm{A}$ ), (3) about one $\mathrm{Z}$ or A molecule binds to the activated site, and (4) this binding effectively "switches" the fluorescence $\tau$ distribution of the PSII unit to a state with a decreased fluorescence $\tau$ and emission intensity (a "dimmer switch" concept). This binding is suggested to cause the formation of an exciton trap with a rapid intrinsic rate constant of heat dissipation. Statistical analysis of the data yields an equilibrium association constant, $K_{\text {a }}$, that ranges from 0.7 to 3.4 per PSII for the protonated/activated binding site for Z (or A). The model explains (1) the relative fraction of the $\sim 0.5$ ns fluorescence component as a function of both $\mathrm{Z}$ and A concentration and intrathylakoid $\mathrm{pH}$, (2) the dependence of the ratio of $F^{\prime}{ }_{\mathrm{m}} / F_{\mathrm{m}}$ on the fraction of the $0.5 \mathrm{~ns}$ fluorescence $\tau$ component (where $F_{\mathrm{m}}^{\prime}$ and $F_{\mathrm{m}}$ are maximal fluorescence intensities in the presence and the absence of a $\mathrm{pH}$ gradient), and (3) the dependence of the ratio of $F_{\mathrm{m}}^{\prime} / F_{\mathrm{m}}$ on the concentration of $\mathrm{Z}$ and $\mathrm{A}$ and the intrathylakoid $\mathrm{pH}$.
\end{abstract}

Interest in the molecular mechanisms used by higher plants to adapt and acclimate to light levels in excess of that used in photosynthesis has recently increased. One possible

\footnotetext{
A.M.G. and G. were supported by a training grant (DOE 92ER20095) from the Triagency (DOE/NSF/USDA) Program and its extension (DBI 96-02240) from the NSF for Collaborative Research in Plant Biology. V.P.S. was supported by USDA Grant 94-37306-0343. A.M.G. thanks the Australian National University (ANU) Research School of Biological Sciences (RSBS) for a research fellowship. T.L.H. and the Laboratory for Fluorescence Dynamics at the University of Illinois were supported by NIH Grant RR03155. The writing of this work was completed when Govindjee was on sabbatical leave at RSBS, ANU, Canberra, supported by an ANU fellowship.

* To whom correspondence should be addressed: University of Illinois, 265 Morrill Hall, MC-116, 505 South Goodwin Ave., Urbana, IL 61801-3707. Fax: 217-244-7246. E-mail: gov@uiuc.edu.

$\doteqdot$ Photobioenergetics Group, ANU/RSBS.

$\S$ Departments of Biochemistry and Plant Biology and Center for Biophysics and Computational Biology, UIUC.

"Laboratory for Fluorescence Dynamics, Physics Department, UIUC.
}

photoprotective mechanism involves xanthophyll cycledependent thermal dissipation of excess absorbed light energy in the light-harvesting complexes of photosystem II (PSII) $(1-8)$. Light harvesting in the PSII antenna and the xanthophyll cycle-dependent heat dissipation mechanism are related to the structure and organization of the PSII pigmentproteins. The PSII holochrome is composed of (a) the PSII core that includes chlorophyll proteins CP43 and CP47 and reaction center proteins D1, D2, and cytochrome $b_{559}$, (b) the minor inner antenna, labeled as CP24, CP26, and CP29, and (c) the major peripheral antenna complex that includes trimeric assemblies of the light-harvesting complex (LHC) IIb (9). The peripheral and inner antennae contain both chlorophylls (Chls) $a$ and $b$ while the core exclusively contains Chl $a$ and lacks Chl $b$. Like the Chl $b$, the xanthophylls lutein and neoxanthin are also distributed almost exclusively in the peripheral/inner antenna complexes. In 
contrast to lutein and neoxanthin, the PSII pool of xanthophyll cycle pigments violaxanthin $(\mathrm{V})$, antheraxanthin $(\mathrm{A})$, and zeaxanthin $(\mathrm{Z})$ is preferentially located in the minor $\mathrm{CP}$ complexes $(80 \%)$ relative to the peripheral LHCIIb $(20 \%)$ (10). The PSII core is enriched in $\beta$-carotene and lacks most xanthophylls (10). The xanthophyll cycle-dependent heat dissipation mechanism functions independently of the LHCIIb level per PSII, as indicated by experiments with $\mathrm{Chl} b$ deficient and $\mathrm{Chl} b$-less mutants of barley, and is therefore believed to be largely associated with the CP complexes of the inner PSII antenna or core (reviewed in ref 7).

Exposure of plants to excess light not only leads to reduced photosynthesis but also leads to quenching of chlorophyll fluorescence (called nonphotochemical quenching, NPQ). The details of this quenching mechanism are under debate $(1-8)$. Nevertheless, it is known that both $\Delta \mathrm{pH}$ and the pigments of the xanthophyll cycle are involved in this process (reviewed in refs 1,4, and 7). Several qualitative models for the combined effects of $\Delta \mathrm{pH}$ and the pigments of the xanthophyll cycle have been proposed earlier (see refs 1, 4, and 7). Here, we report, compare, and analyze the effects of intrathylakoid $\Delta \mathrm{pH}$ and xanthophyll cycle pigments on both the Chl $a$ fluorescence lifetime distributions and the pulse-amplitude modulation (PAM) intensity profiles in thylakoids from four different plants, namely, spinach (Spinacea oleracea L.), wild-type (WT) variety and chlorophyll $b$ deficient nuclear gene mutant chlorina f104 (clof104) barley (Hordeum vulgare L.), and Arabidopsis thaliana L. cv. Columbia. Fluorescence lifetime measurements provide direct information on the fluorescence quantum yield and, thus, on the rate constants of the decay of the excited state. On the other hand, it is easier to measure fluorescence intensity $(F)$ by commercial pulse-amplitude modulation (PAM) fluorometers. However, the intensity alone cannot distinguish between changes in the absorption cross section and the fluorescence quantum yield. To explain the observed results, we present a new quantitative model that describes the cumulative effects of both the chloroplast intrathylakoid $\mathrm{pH}$ and the xanthophyll cycle pigments $\mathrm{Z}$ and

\footnotetext{
${ }^{1}$ Abbreviations: A, antheraxanthin; $c_{x}$, fluorescence lifetime center corresponding to the maximal amplitude value of the fluorescence lifetime distribution component labeled as $x$; Chl, chlorophyll; CPX, chlorophyll binding protein of PSII with molecular mass $X$; Diuron (DCMU), 3-(3,4-dichlorophenyl)-1,1-dimethylurea; DTT, dithiothreitol; $F_{\mathrm{m}(0)}$, maximal Chl $a$ fluorescence intensity with all $\mathrm{Q}_{\mathrm{A}}$ reduced in the beginning of the experiment; $F_{\mathrm{m}}$, maximal $\mathrm{Chl} a$ fluorescence intensity with all $\mathrm{Q}_{\mathrm{A}}$ reduced in the absence of the proton gradient but in the presence of zeaxanthin (or antheraxanthin); $F^{\prime}$ m, maximal Chl a fluorescence intensity with all $\mathrm{Q}_{\mathrm{A}}$ reduced in the presence of the proton gradient and of zeaxanthin (or antheraxanthin); $F_{\mathrm{o}}$, fluorescence intensity when all $\mathrm{Q}_{\mathrm{A}}$ is in the oxidized state; $f_{x}$, fractional intensity of a fluorescence lifetime distribution component labeled as $x ; K_{\mathrm{a}}$, association equilibrium constant for binding of $\mathrm{Z}$ or $\mathrm{A}$; LHCIIb, main lightharvesting pigment - protein complex of PSII; NPQ, nonphotochemical quenching of $\mathrm{Chl} a$ fluorescence; PAM, pulse-amplitude modulation fluorometer; PFD, photon flux density; PSI, photosystem I; PSII, photosystem II; P680, reaction center Chl $a$ molecule, primary electron donor of PSII; $\mathrm{Q}_{\mathrm{A}}$, primary quinone electron acceptor of PSII; V, violaxanthin; $w_{x}$, width at half-maximum of the fluorescence lifetime distribution component labeled as $x$; WT, wild type; Z, zeaxanthin; $\Delta \mathrm{pH}$, trans-thylakoid membrane proton gradient; $\tau_{x}$, fluorescence lifetime of component $x ;\langle\tau\rangle=f_{x} \tau_{x}$, average fluorescence lifetime in the absence of the trans-thylakoid membrane $\mathrm{pH}$ gradient; $\left\langle\tau^{\prime}\right\rangle=\Sigma f_{x} \tau_{x}$, average fluorescence lifetime in the presence of the trans-thylakoid membrane $\mathrm{pH}$ gradient.
}

A on the PSII Chl $a$ fluorescence lifetime distributions and intensity.

\section{MATERIALS AND METHODS}

Plant Material and Thylakoid Preparation. Fresh spinach (S. oleracea) leaves were obtained locally and stored for at least $12 \mathrm{~h}$ (dark, $4{ }^{\circ} \mathrm{C}$ ) before thylakoid isolation. Wildtype (WT) (H. vulgare L. cv. Donaria) and nuclear gene mutant chlorina f104 (clof104) barley plants were grown in the greenhouse. Barley seeds were germinated on a heating pad in potting soil covered with a layer of vermiculite. Plants were watered twice daily and fertilized once with a $20 \mathrm{~N}: 20$ $\mathrm{P}: 20 \mathrm{~K}$ fertilizer applied at a concentration of $473 \mathrm{ppm} \mathrm{N}$. Natural light was supplemented with high-intensity discharge lamps; the minimum photon flux density (PFD) was $400 \pm$ $100 \mu \mathrm{mol}$ of photons $\mathrm{m}^{-2} \mathrm{~s}^{-1}$ and the photo period was 14 $\mathrm{h}$ of light and $10 \mathrm{~h}$ of dark. A. thaliana L. cv. Columbia plants were grown in a growth chamber with a PFD of 230 $\mu$ mol of photons $\mathrm{m}^{-2} \mathrm{~s}^{-1}$, a photo period of $11.5 \mathrm{~h}$, and a relative humidity of $90 \%$. Barley plants were harvested after 8-10 days, whereas Arabidopsis plants were harvested after 8-10 weeks of growth. Leaves were dark adapted for at least $12 \mathrm{~h}$ at room temperature, then cut at their base, wrapped in a wet paper towel, and chilled in the dark for $1-2 \mathrm{~h}$ in a bag of ice in a $4^{\circ} \mathrm{C}$ refrigerator. All thylakoid isolation procedures were performed in a darkened cold room $\left(7^{\circ} \mathrm{C}\right)$ under dim green light using chilled wares. The leaves $(8-10 \mathrm{~g})$ were cut into $2-3 \mathrm{~cm}$ pieces and ground using two to three 1-s bursts in a Waring blender in $100 \mathrm{~mL}$ of a slushy grinding buffer containing $0.33 \mathrm{M}$ dextrose, $50 \mathrm{mM}$ $\mathrm{Na}_{2} \mathrm{HPO}_{4} \cdot 7 \mathrm{H}_{2} \mathrm{O}, 50 \mathrm{mM} \mathrm{KH} \mathrm{PO}_{4}, 25 \mathrm{mM} \mathrm{KCl}, 5 \mathrm{mM}$ $\mathrm{MgCl}_{2}, 0.1 \% \mathrm{BSA}$, and $0.2 \%$ sodium ascorbate, $\mathrm{pH}$ 6.5. The brie was gently vacuum filtered through a $41 \mu \mathrm{m}$ nylon filter (Spectra/Mesh). The filtrate was centrifuged for $10 \mathrm{~min}$ at $1500 \mathrm{~g}$ in an SS-34 (Sorvall) rotor at $4{ }^{\circ} \mathrm{C}$. The pellet was gently resuspended in buffer A containing $0.33 \mathrm{M}$ sorbitol, $4 \mathrm{mM}$ EDTA, $5 \mathrm{mM} \mathrm{MgCl} 2,2 \mathrm{mM} \mathrm{MnCl}_{2}, 0.1 \mathrm{M}$ HEPES, and $0.2 \% \mathrm{BSA}, \mathrm{pH}$ 7.6. The reaction mixture (buffer $\mathrm{B}$ ) contained $0.1 \mathrm{M}$ sucrose, $10 \mathrm{mM} \mathrm{NaCl}, 10 \mathrm{mM} \mathrm{KCl}, 5 \mathrm{mM}$ $\mathrm{MgCl}_{2}, 10 \mathrm{mM}$ Tricine, $1 \mathrm{mM} \mathrm{KH} \mathrm{PO}_{4}$, and $0.2 \% \mathrm{BSA}, \mathrm{pH}$ 8.0. The following ingredients were added to buffer $\mathrm{B}$ immediately prior to the experiments: $30 \mathrm{mM}$ sodium ascorbate to mediate deepoxidation of violaxanthin to zeaxanthin, $50 \mu \mathrm{M}$ methyl viologen to mediate linear electron transport, and $0.3 \mathrm{mM}$ ATP to fuel ATP hydrolysis. We call this final reaction mixture buffer $\mathrm{C}$. The $\mathrm{Chl}$ concentration was determined according to the equations of Porra et al. (12).

Fluorescence Measurements. Fluorescence lifetimes ( $\tau \mathrm{s}$ ) were measured by using a cross-correlation, multifrequency, phase and modulation fluorometer (ISS Inc., Champaign, IL). Samples were excited with $610 \mathrm{~nm}$ light from the output of a cavity-dumped rhodamine $6 \mathrm{G}$ dye laser (Coherent, Palo Alto, CA) synchronously pumped by a mode-locked $\mathrm{Nd}$ : YAG laser. Chl $a$ fluorescence was observed at wavelengths longer than $620 \mathrm{~nm}$ through a Hoya R-64 long pass filter. A scattering solution of glycogen in distilled water was used as the lifetime reference ( $0 \mathrm{~ns})$, and a Corion $610 \mathrm{~nm}$ interference filter was placed in the emission path to isolate the scattering signal. Excitation path and emission path polarizers were set at $0^{\circ}$ and $55^{\circ}$, respectively, to eliminate polarization artifacts in the fluorescence decay measurements 
(13). Phase and modulation data were collected at multiple modulation frequencies ranging from 7 to $300 \mathrm{MHz}$ and were subsequently analyzed using Globals Unlimited analysis software (University of Illinois, Urbana, IL). Here, we accept that the $\mathrm{Chl} a$ fluorescence lifetimes of pigment-protein complexes are most realistically modeled assuming a distribution(s) of lifetimes (14-18), in accordance with the concepts of protein dynamics and conformational substates (19). Data were fit to a bimodal, Lorentzian lifetime distribution model. This model includes two components, $c_{1}$ and $c_{2}$, that are characterized by two lifetimes, $\tau_{1}$ and $\tau_{2}$, by full widths at half-maximum, $w_{1}$ and $w_{2}$, and by relative fractional intensities, $f_{1}$ and $f_{2}$ (where $f_{1}+f_{2}=1.0$ ). Additional information on phase and modulation fluorometry and the use of lifetime distribution models can be found in the literature $(14,15,20)$.

In addition to the lifetime of fluorescence measurements, changes in the $\mathrm{Chl} a$ fluorescence intensity were recorded with a pulse-amplitude modulation fluorometer (PAM 103, Heinz-Walz, Effeltrich, FRG). In all cases, both $F_{\mathrm{m}}$ and $F_{\mathrm{m}}^{\prime}$ were obtained under conditions where the primary quinone electron acceptor of PSII, $\mathrm{Q}_{\mathrm{A}}$, was reduced to $\mathrm{Q}_{\mathrm{A}}{ }^{-}$either by a $2 \mathrm{~s}$ pulse of white light PFD $\approx 10000 \mu \mathrm{mol}$ of photons $\mathrm{m}^{-2} \mathrm{~s}^{-1}$ (from a Schott model KL-1500 lamp, filtered through a Walz DT-Cyan infrared filter) or after the addition of 10 $\mu \mathrm{M}$ DCMU to the reaction mixture during a continuous exposure to white light $\left(\mathrm{PFD}=500 \mu \mathrm{mol}\right.$ of photons $\mathrm{m}^{-2}$ $\mathrm{s}^{-1}$.

Protocol for Xanthophyll Cycle-Dependent Nonphotochemical Quenching of Chl a Fluorescence. The protocol for our experiments involved the following eight steps. Step 1 was exposure of isolated thylakoid membranes to white light (PFD $=500 \mu \mathrm{mol}$ of photons $\mathrm{m}^{-2} \mathrm{~s}^{-1}$, passing through a Corning CS1-75 infrared filter) which led to the acidification of the intrathylakoid space (lumen). This acidification activated the deepoxidase ( $\mathrm{pH}$ optimum, 5.2) that converted the diepoxide $\mathrm{V}$ to the monoepoxide $\mathrm{A}$ and to epoxide-free $\mathrm{Z}(23,24)$. The steady-state $[\mathrm{Z}]+[\mathrm{A}]$ was further varied at this time and at this step by the addition of different, but still low, concentrations of the sulfhydryl reagent dithiothreitol (DTT) that specifically and quantitatively inhibited the deepoxidase (25) without inhibiting either the light-driven or ATPase-mediated proton pumps $(26,27)$. In step 2, a high concentration $(3 \mathrm{mM})$ of DTT was added for two purposes, first to stop further [Z] $+[\mathrm{A}]$ formation and second to ensure thiol activation of the chloroplast ATPase (26). Importantly, reversion of $\mathrm{Z}$ and $\mathrm{A}$ back to $\mathrm{V}$ did not occur in our system since exogenous $\mathrm{NAD}(\mathrm{P}) \mathrm{H}$ was not added to the reaction mixture to activate the zeaxanthin epoxidase enzyme (28). In step 3, the maximal steady-state fluorescence intensity, $F^{\prime}$ m, was measured when the $\mathrm{pH}$ gradient was created by both light-driven electron transport and ATP hydrolysis. In step 4, diuron [3-(3,4-dichlorophenyl)-1,1dimethylurea], an inhibitor of electron transport between the $\mathrm{Q}_{\mathrm{A}}$ and the secondary quinone $\mathrm{Q}_{\mathrm{B}}$, was added to eliminate photochemical quenching of $\mathrm{Chl} a$ fluorescence by the oxidized primary quinone electron acceptor $\mathrm{Q}_{\mathrm{A}}(29)$. Diuron also completely blocked the light-driven proton pump without inhibiting the ATPase proton pump (26). Methyl viologen, which was added prior to illumination in buffer $\mathrm{C}$, was present to eliminate changes in the transfer of excitation energy from PSII to PSI $(26,30)$. In step 5, chilling the reaction mixture to less than $5{ }^{\circ} \mathrm{C}$ slowed the $\Delta \mathrm{pH}$ dissipation and allowed fluorescence measurements at steady-state $\mathrm{pH}$ conditions (16). In step 6, the steady-state fluorescence lifetimes $\left(\tau_{\mathrm{f}} \mathrm{s}\right)$ and $F_{\mathrm{m}}^{\prime}$ were determined under conditions when the proton gradient was created by ATPase only. In step 7 , the protonophoric uncoupler nigericin was used to dissipate the transmembrane proton gradient. In step 8, the fluorescence lifetimes $\left(\tau_{\mathrm{f}} \mathrm{s}\right)$ and intensities $\left(F_{\mathrm{m}}\right)$ were measured again. Xanthophyll cycle pigment analyses were done as described by Gilmore and Yamamoto (31).

pH Measurements. The intrathylakoid $\mathrm{pH}$ was measured using 9-aminoacridine as a probe (32). This method is suitable for measurements of $\mathrm{pH}$ gradient that is greater than 1.0 (33). The 9-aminoacridine fluorescence intensity was measured using a SLM-8100 spectrofluorometer (Spectronic Instruments, Champaign, IL) with excitation at $400 \mathrm{~nm}(4$ $\mathrm{nm}$ slit) and emission monitored at $450 \mathrm{~nm}$ (4 nm slit). The $3 \mathrm{~mL}$ sample $\left(15^{\circ} \mathrm{C}\right)$ was illuminated, while being stirred, from the side using the PAM fiberoptics and light from a Schott KL-1500 microscope lamp, passed through both a Schott RG (>610 $\mathrm{nm}$ ) and a Walz (infrared) DT cyan filter, resulting in a final PFD of $1600 \mu \mathrm{mol}$ of photons $\mathrm{m}^{-2} \mathrm{~s}^{-1}$. The reaction mixture was buffer B plus $50 \mu \mathrm{M}$ methyl viologen and $0.3 \mathrm{mM}$ ATP. Five millimolar DTT and $3 \mu \mathrm{M}$ 9-aminoacridine were added prior to illumination, $10 \mu \mathrm{M}$ DCMU was added after 5 min of illumination, and $2 \mu \mathrm{M}$ nigericin was added after 10 min of illumination. Data were averaged for three independent thylakoid samples.

Iterative Model Fitting Routine. The best fitting $\mathrm{pH}$ values and the mean $( \pm \mathrm{SD})$ relative equilibrium association constant $K_{\mathrm{a}}$ values (for [Z]/PSII and [A]/PSII) were determined using the iterative Solver routine in Excel 5.0 (Microsoft). The best fits were determined by maximizing the values of both the coefficient of determination $\left(r^{2}\right)$ and an analysis of variance $(F$-test $=$ one-tailed probability that the variations in the model were not significantly different from the variations in the data).

\section{RESULTS}

Using thylakoids from spinach, wild-type (WT) and chlorina fl04 barley, and Arabidopsis, we have reinvestigated the effects of the $\Delta \mathrm{pH}$ (created by light and/or by ATPase) and the concentrations of $\mathrm{Z}$ and $\mathrm{A}$ (as varied by the addition of DTT) on the maximal chlorophyll $a$ fluorescence intensities and lifetimes.

Effect of [DTT] on the Concentration of Antheraxanthin and Zeaxanthin. The violaxanthin deepoxidase catalyzes the conversion of violaxanthin (V) first to antheraxanthin (A) and then to zeaxanthin (Z). DTT is known to inhibit this deepoxidase (25). Figure 1A shows that addition of up to $0.4 \mathrm{mM}$ DTT to wild-type (WT) barley thylakoids decreases the relative concentration of zeaxanthin (diamonds) by about 4-fold from a fractional value of about 0.4 to 0.1 of $[\mathrm{V}+\mathrm{Z}$ $+\mathrm{A}]$. In contrast to zeaxanthin, changes in the relative concentration of antheraxanthin (squares) are smaller; we observe a slight increase with a plateau at about $0.2 \mathrm{mM}$ DTT. Then, there is a slight decrease of $[\mathrm{A}]$ at about $1 \mathrm{mM}$ [DTT]. The sum of $[\mathrm{Z}]$ and $[\mathrm{A}]$ (circles) decreases with increasing [DTT]. Relative changes in $[\mathrm{Z}]$ and in $[\mathrm{A}]$ are shown when we plot the fraction of $[\mathrm{Z}]$ or $[\mathrm{A}]$ per total xanthophylls $[\mathrm{V}+\mathrm{Z}+\mathrm{A}]$ as a function of the fraction of 
WT Barley
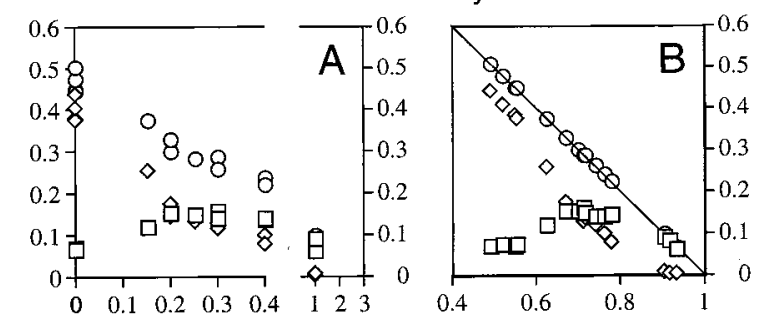

Arabidopsis

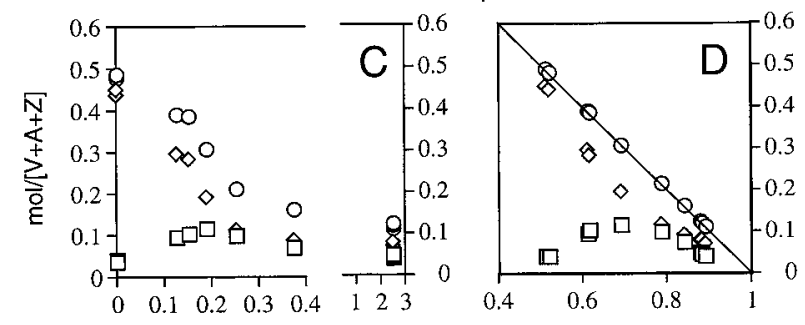

Spinach

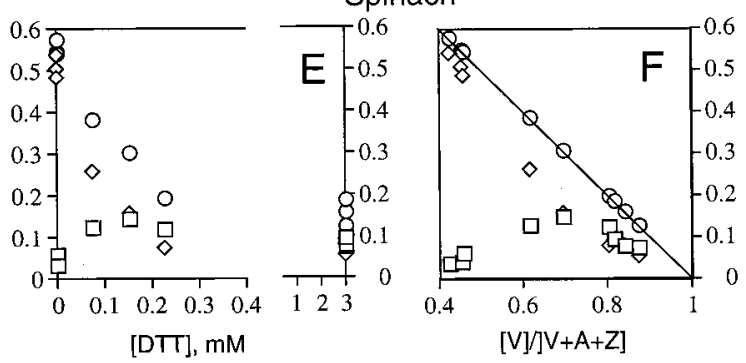

FIGURE 1: Dependence of the relative concentration of antheraxanthin (squares), zeaxanthin (diamonds), and $\mathrm{Z}+\mathrm{A}$ (circles) on dithiothreitol (DTT) concentration (panels A, C, and E) and on the relative concentration of violaxanthin (panels $\mathrm{B}, \mathrm{D}$, and $\mathrm{F}$ ) for thylakoids from WT barley, Arabidopsis, and spinach. Thylakoids were suspended, at $15^{\circ} \mathrm{C}$, in $3 \mathrm{~mL}$ of buffer $\mathrm{C}$; [Chl $a+b$ ] was $15 \mu \mathrm{M}$. In all experiments, different concentrations of DTT were added prior to actinic illumination.

violaxanthin to the total xanthophylls (Figure 1B). At high $(0.8-1 \mathrm{mM})$ violaxanthin concentrations, $[\mathrm{A}]$ decreases just as $[\mathrm{Z}]$ does. As expected, the fraction of $[\mathrm{Z}]+[\mathrm{A}]$ decreases linearly with the fraction of V. Qualitatively, results similar to that in barley were obtained with Arabidopsis (panels C and D of Figure 1) and spinach (panels $\mathrm{E}$ and $\mathrm{F}$ of Figure 1 ), confirming the generality of the phenomenon under investigation.

pH Measurements. Using 9-aminoacridine fluorescence (33), we measured the intrathylakoid $\mathrm{pH}$ under three experimental conditions ( $\mathrm{pH}$ gradient created by light, created by ATPase only, and dissipated by nigericin) in Arabidopsis (Figure 2A) and spinach (Figure 2B) thylakoids. The shaded bars show that the intrathylakoid $\mathrm{pH}$ is $\sim 4.5$ under conditions when the $\mathrm{pH}$ gradient is created by light and is $\sim 5.3$ when the $\mathrm{pH}$ gradient is created by ATP hydrolysis only. The largest value (about 8) was obtained when the $\mathrm{pH}$ gradient was dissipated with nigericin. We are aware that the value of the measurement in the $\mathrm{pH} 7-8$ region, using 9-aminoacridine, is unreliable due to the lower sensitivity of the aminoacridine method at small values $(<1.5)$ of the $\mathrm{pH}$ gradient (33). Since the intrathylakoid $\mathrm{pH}$ equilibrates with the reaction mixture (buffer $\mathrm{B}$ ), which was measured to be pH 8 (hatched bar), the intrathylakoid pH must also be 8 . Unshaded bars show the $\mathrm{pH}$ values predicted from a theoretical model (to be discussed later; see Discussion).

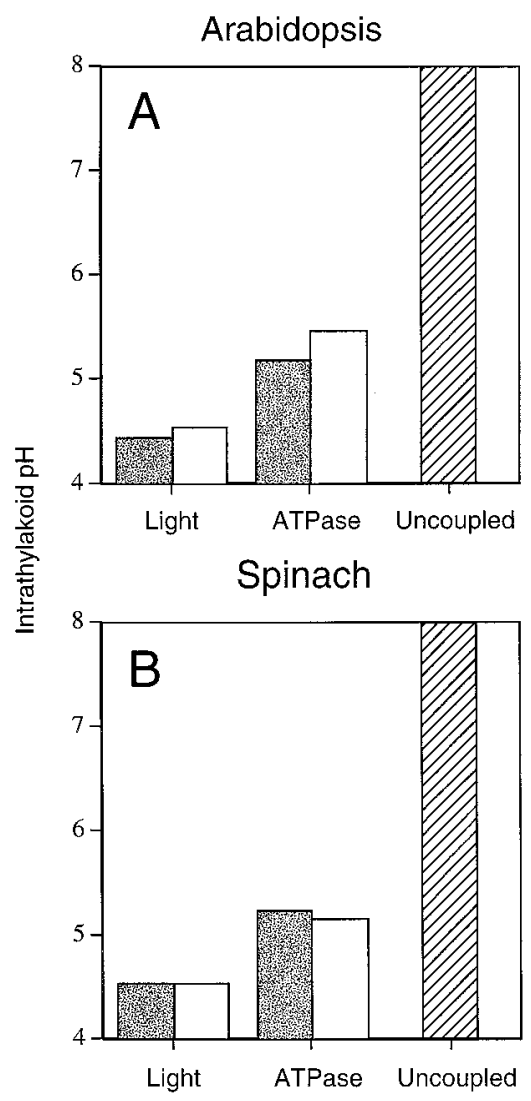

FIGURE 2: Intrathylakoid $\mathrm{pH}$, measured by the 9-aminoacridine uptake (shaded bars), in Arabidopsis and spinach thylakoids under light-saturating (Light) and ATPase-mediated (ATPase) conditions. The hatched bar represents the $\mathrm{pH}$ of the uncoupled reaction mixture (buffer B). Unshaded bars show the results calculated from the theoretical model (see Discussion). The reaction mixture was buffer B plus $50 \mu \mathrm{M}$ methyl viologen and $0.3 \mathrm{mM}$ ATP. Five millimolar DTT and $3 \mu \mathrm{M}$ 9-aminoacridine were added prior to illumination. Ten micromolar DCMU and $2 \mu \mathrm{M}$ nigericin were added, respectively, after 5 and 10 min of illumination.

Results with spinach thylakoids were almost identical with those for Arabidopsis.

Effect of [DTT] on Nonphotochemical Quenching of Chlorophyll a Fluorescence. Here, we report the effects of the xanthophyll cycle pigment concentration (changed by the addition of DTT) on the pulse-amplitude modulation (PAM) chlorophyll a fluorescence intensity. Figure $3 \mathrm{~A}$ shows a typical Chl $a$ fluorescence intensity measurement for a spinach thylakoid suspension. The encircled numbers 1 through 8 refer to the steps in the experimental protocol (see Materials and Methods). After switching on a weak measuring light, we measured $F_{\mathrm{o}}$ (minimum fluorescence yield); then, after switching on a strong (actinic) light flash, we measured $F_{\mathrm{m}(0)}$ (maximum fluorescence yield in the presence of a $\mathrm{pH}$ gradient but in the absence, we believe, of $\mathrm{Z}$ or $\mathrm{A}$ at the binding site). After switching on another strong, but continuous, light (see "On"), we observed first an increase and then a decrease in fluorescence (the Kautsky effect). After adding the same strong actinic light flash as before, we observed only small additional increases (see small spikes) in fluorescence yield. The difference between maxima of the spikes (called $F^{\prime}{ }_{\mathrm{m}}$ ) and $F_{\mathrm{m}(0)}$ is usually considered as a measure of nonphotochemical quenching. As shown in Figure 3A, after steps 2 (high DTT addition), 3 (measurement of $F_{\mathrm{m}}^{\prime}$ ), 4 (DCMU addition), and 5 (chilling), 


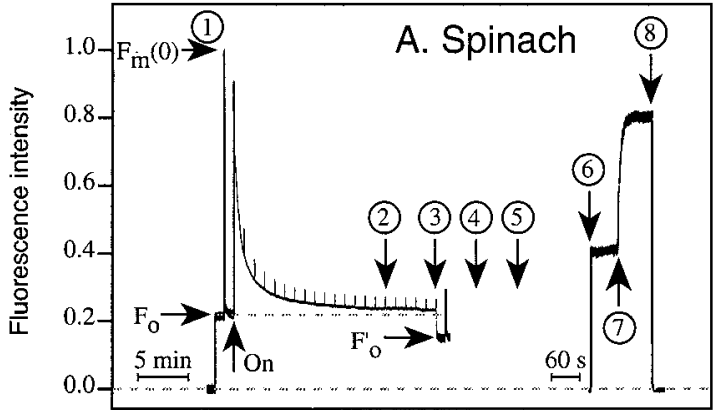

Time
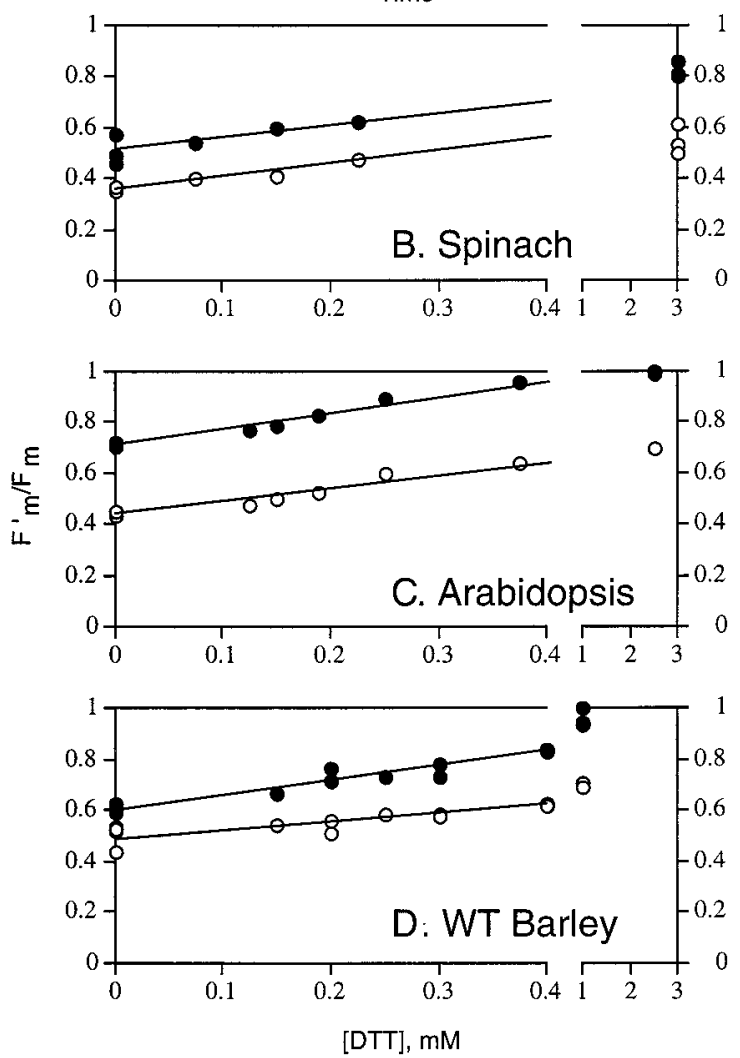

FIGURE 3: Effect of [DTT] on chlorophyll $a$ fluorescence yields. Panel A shows the protocol of the experiment. The numbers refer to the steps of the protocol described in Materials and Methods. Panels B, C, and D show the dependence of $F_{\mathrm{m}}^{\prime} / F_{\mathrm{m}}$ (where $F_{\mathrm{m}}^{\prime}$ and $F_{\mathrm{m}}$ are the maximum fluorescence yields obtained in the presence and the absence of the $\mathrm{pH}$ gradient) on [DTT] for thylakoids from spinach, Arabidopsis, and WT barley, respectively. Open circles $\left(F_{\mathrm{m}}^{\prime}\right.$ measured in step $3 ; F_{\mathrm{m}}$ measured in step 8 ) represent data when the $\mathrm{pH}$ gradient was created by saturating light, whereas solid circles $\left(F_{\mathrm{m}}^{\prime}\right.$ measured in step $6 ; F_{\mathrm{m}}$ measured in step 8) represent data when the $\mathrm{pH}$ gradient was created by ATPase only. Data shown here are from the same samples as those used in Figure 1. The reaction mixture was buffer B plus $50 \mu \mathrm{M}$ methyl viologen and $0.3 \mathrm{mM}$ ATP. Different concentrations of DTT were added prior to illumination. Ten micromolar DCMU and 2 $\mu \mathrm{M}$ nigericin were added at step 4 and step 7, respectively (see panel A).

a new $F^{\prime}{ }_{\mathrm{m}}$ was measured (step 6). Note that, after step 3, the strong continuous light was turned off, and a new $F_{\mathrm{o}}$, called $F^{\prime}{ }_{\mathrm{o}}$, was obtained. Then, in step 7, nigericin was added to measure $F_{\mathrm{m}}$ (maximum fluorescence yield in the absence of the $\mathrm{pH}$ gradient). For the case when the $\mathrm{pH}$ gradient was created by light, $F^{\prime}$ m was measured after step 3 (i.e., before turning off the actinic light); for the case when the $\mathrm{pH}$ gradient was created by ATPase only, $F^{\prime}$ m was measured at step 6. In the remainder of Figure 3, we plotted the influence of increasing concentrations of DTT (added at the very beginning of the experiment) on the ratio of maximal Chl $a$ fluorescence intensity $F_{\mathrm{m}}^{\prime}$ to $F_{\mathrm{m}}$ under either light-saturating (open circles, $F_{\mathrm{m}}^{\prime}$ at step 3 divided by $F_{\mathrm{m}}$ at step 8 ) or ATPase-mediated (closed circles, $F^{\prime}$ m at step 6 divided by $F_{\mathrm{m}}$ at step 8) conditions for intrathylakoid acidification in spinach (panel B), Arabidopsis (panel C), and WT barley (panel D) thylakoids. Although the nonphotochemical quenching (NPQ) has traditionally been plotted as $\left(F_{\mathrm{m}}-\right.$ $\left.F_{\mathrm{m}}^{\prime}\right) / F_{\mathrm{m}}^{\prime}$, we have plotted here the ratio of $F_{\mathrm{m}}^{\prime}$ to $F_{\mathrm{m}}$ as a function of [DTT] because, as we will see later (Figure 4), this is linearly related to the concentration of bound zeaxanthin $(\mathrm{Z})$ and antheraxanthin $(\mathrm{A})$ : increasing the concentration of bound $\mathrm{Z}$ and $\mathrm{A}$ decreases the $F_{\mathrm{m}}^{\prime} / F_{\mathrm{m}}$. When the $\mathrm{pH}$ gradient is created either by light (bottom curves, open circles) or by ATPase (top curves, closed circles), $F_{\mathrm{m}}^{\prime} / F_{\mathrm{m}}$ increases with increasing [DTT] in all the three species. Generally, the influence of [DTT] on $F^{\prime}{ }_{\mathrm{m}} / F_{\mathrm{m}}$ saturates above $1 \mathrm{mM}$ DTT, which is consistent with the known inhibition of deepoxidation. Clearly, $F_{\mathrm{m}}^{\prime} / F_{\mathrm{m}}$ is significantly lower when the $\mathrm{pH}$ gradient is created by light than by ATPase. This difference is due to the higher $\Delta \mathrm{pH}$ created by the light than by the ATPase (see Figure 2).

Figure 4 shows the dependence of $F_{\mathrm{m}}^{\prime} / F_{\mathrm{m}}$, which characterizes nonphotochemical quenching of Chl $a$ fluorescence, on the relative concentration of zeaxanthin (left panels), antheraxanthin (middle panels), and their sum (right panels) for barley (top panels), for Arabidopsis (middle horizontal panels), and for spinach (bottom panels) thylakoids. The quenching of Chl $a$ fluorescence, as measured by $F^{\prime}{ }_{\mathrm{m}} / F_{\mathrm{m}}$, is stronger at higher $[\mathrm{Z}]$, whether the $\mathrm{pH}$ gradient was created by light (open circles) or by ATPase (closed circles). It is evident from this figure that the quenching of Chl $a$ fluorescence is higher when the $\Delta \mathrm{pH}$ is higher (created by light). This confirms the general view that both the $\mathrm{pH}$ gradient and the $[\mathrm{Z}]$ are important for the quenching of $\mathrm{Chl}$ $a$ fluorescence. Panels $\mathrm{B}, \mathrm{E}$, and $\mathrm{H}$ show the dependence of $F^{\prime}{ }_{\mathrm{m}} / F_{\mathrm{m}}$ on [A]. We observe that when [Z] is low (at high [DTT], see topmost points, both for open circles and for closed circles), increasing [A] increases the quenching of Chl $a$ fluorescence (lowering of $F_{\mathrm{m}}^{\prime} / F_{\mathrm{m}}$ ). This suggests A is a quencher of $\mathrm{Chl} a$ fluorescence under these conditions. However, when [Z] is significantly higher than $[\mathrm{A}]$, we observe a change in $F_{\mathrm{m}}^{\prime} / F_{\mathrm{m}}$ apparently in the opposite direction with increasing [A]; however, it should be realized that A converts directly to $\mathrm{Z}$. The behavior of $F_{\mathrm{m}}^{\prime} / F_{\mathrm{m}}$ with increasing $[\mathrm{Z}]$ or $[\mathrm{A}]$ is explained by suggesting that the quenching of Chl $a$ fluorescence depends on the sum of [A] and $[\mathrm{Z}]$. This conclusion becomes obvious when we plot $F_{\mathrm{m}}^{\prime} / F_{\mathrm{m}}$ as a function of $[\mathrm{Z}+\mathrm{A}]$ (see panels $\mathrm{C}, \mathrm{F}$, and $\mathrm{I}$ ). Whether the $\mathrm{pH}$ gradient is created by light (open circles in each panel) or by ATPase (closed circles in each panel), the $F_{\mathrm{m}}^{\prime} / F_{\mathrm{m}}$ is found to decrease progressively with increasing $[\mathrm{Z}+\mathrm{A}]$.

Concerted Effects of the Intrathylakoid $\mathrm{pH}$ and Xanthophyll Cycle Pigment Concentrations on the Chl a Fluorescence Lifetime Distributions. Figure 5 shows the Chl a fluorescence lifetime distributions in isolated thylakoid membranes of spinach (top panel) and wild-type (WT) barley (bottom panel) under the following conditions: (a) in the absence of nigericin, where a transmembrane $\mathrm{pH}$ gradient $(\Delta \mathrm{pH})$ is present (dashed curves), and (b) in the presence of 


\section{WT Barley}
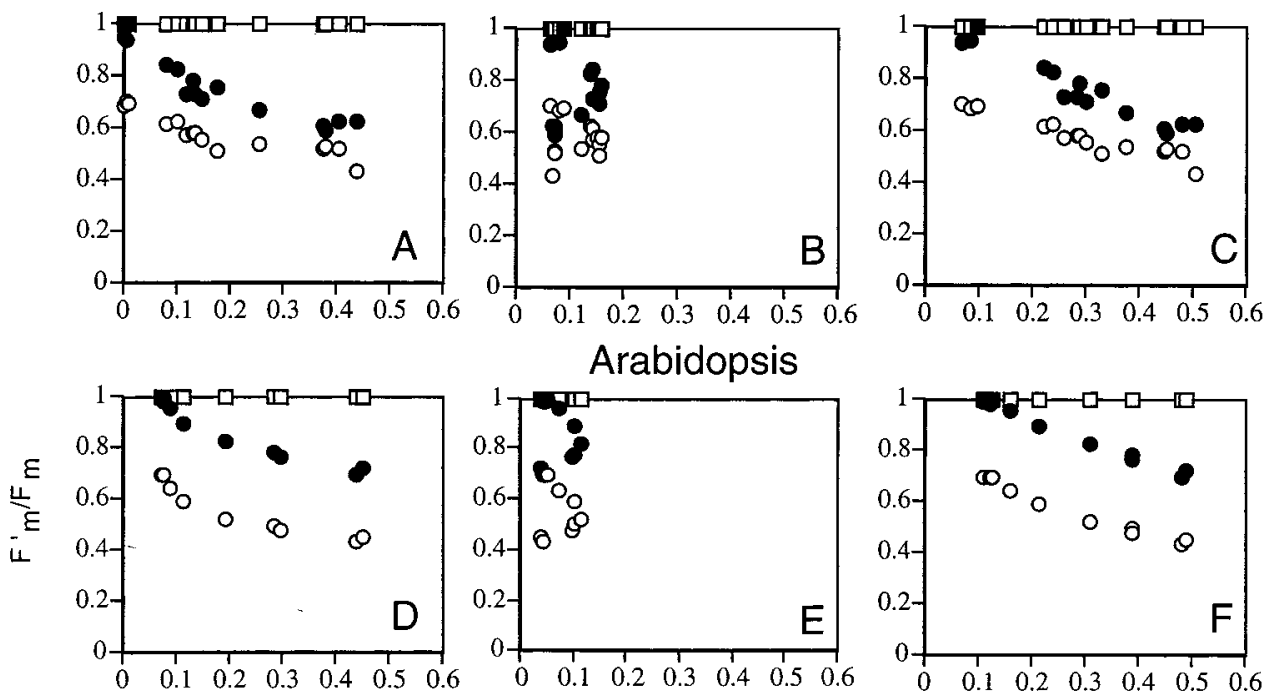

Spinach
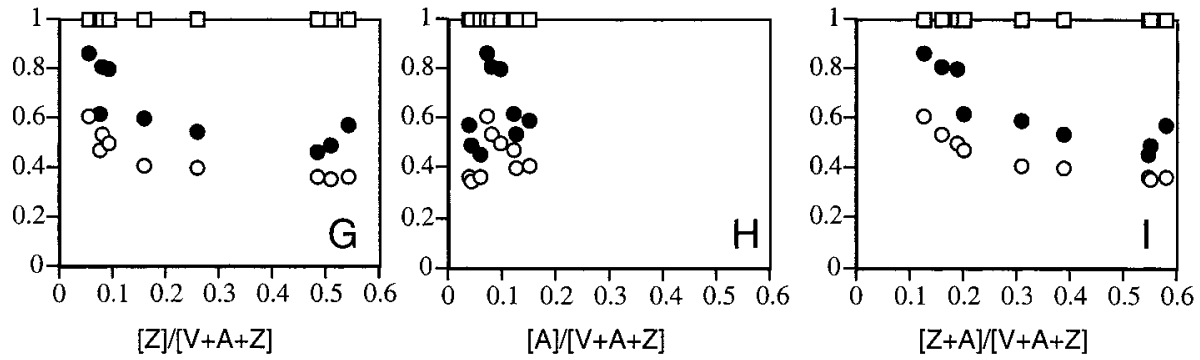

FIGURE 4: Dependence of $F_{\mathrm{m}}^{\prime} / F_{\mathrm{m}}$ (where $F_{\mathrm{m}}^{\prime}$ and $F_{\mathrm{m}}$ are the maximum fluorescence yields obtained in the presence and the absence of the $\mathrm{pH}$ gradient) on the relative concentrations of zeaxanthin ( $\mathrm{Z}$, panels $\mathrm{A}, \mathrm{D}$, and $\mathrm{G})$, antheraxanthin $(\mathrm{A}$, panels $\mathrm{B}, \mathrm{E}$, and $\mathrm{H})$, and $\mathrm{Z}+\mathrm{A}$ (panels C, F, and I) in barley (panels A, B, and C), Arabidopsis (panels D, E, and F), and spinach (panels G, H, and I) thylakoids. Open circles represent data when the $\mathrm{pH}$ gradient was created by saturating light, solid circles represent data when the $\mathrm{pH}$ gradient was created by ATPase only, and squares represent data in the presence of nigericin. All other details are as described in the legend of Figure 3.

nigericin, where a $\Delta \mathrm{pH}$ is absent (solid curves). In the experiments reported here, DTT was added first to decrease the $[\mathrm{Z}]$ and $[\mathrm{A}]$, and then nigericin was added. In the presence of a $\mathrm{pH}$ gradient, we observe two major components of fluorescence in both of the species. We refer to the longlifetime component as $c_{1}$, its fractional intensity as $f_{1}$, and its lifetime center as $\tau_{1}$, whereas the second short-lifetime component is referred to as $c_{2}$, its fractional intensity as $f_{2}$, and its lifetime center as $\tau_{2}$. In spinach, for example, $\tau_{1}$ is $1.8 \mathrm{~ns}$ and $\tau_{2}$ is $\approx 0.46 \mathrm{~ns}$. In the absence of DTT, the component $c_{1}$ has a low $f_{1}$, and the component $c_{2}$ has a high $f_{2}$. Decreasing $[\mathrm{Z}]+[\mathrm{A}]$, by adding DTT, leads to decreases in the $f_{2}$ of the fluorescence lifetime distribution with the short-lifetime center $\left(\tau_{2} \approx 0.46 \mathrm{~ns}\right)$ and increases in the fractional intensity $\left(f_{1}\right)$ of the long-lifetime center $\left(\tau_{1} \approx 1.8\right.$ ns). In barley, similar results were obtained. However, the barley $\tau_{1}$ and $\tau_{2}$ were 1.6 and $0.5 \mathrm{~ns}$, respectively, and the width of the $c_{2}$ distribution was found to be wider $(0.76 \mathrm{~ns})$ than that of $c_{1}(0.5 \mathrm{~ns})$.

In the presence of nigericin, when the trans-thylakoid $\mathrm{pH}$ gradient is absent (see solid curves), the $\mathrm{Chl} a$ fluorescence lifetime was not affected by changes in the [Z] and [A]. Here, the major distribution (with fraction $f_{1}$ ) is, however, centered at $\tau_{1}$ of about $2.2 \mathrm{~ns}$ for spinach thylakoids and about $2.0 \mathrm{~ns}$ for barley thylakoids. It is clear that this component has shifted to slightly higher values from that before nigericin was added; further, the width of the lifetime distribution is wider in the absence of $\Delta \mathrm{pH}$ than in its presence. Note, as shown in Table 1, that (a) these differences vary between spinach and barley and (b) in barley mutant clof104, which lacks most LHCIIb, these differences (17) in widths are much smaller than in the wild type. Thus, it is likely that the above-described differences in widths may also include effects on LHCIIb. These results are understood if we suggest that $\mathrm{pH}$ alone causes some conformational change in the vicinity of chlorophyll molecules in the pigmentprotein complexes.

Table 1 contains the results of analysis of fluorescence data for thylakoids of spinach, WT barley, and barley mutant clof 104, by assuming that there is a linear relationship between the fluorescence intensity ratio $F_{\mathrm{m}}^{\prime} / F_{\mathrm{m}}$ and the fractional intensity of the faster decaying fluorescence lifetime component $c_{2}$. All data for each species were linked to form a global data set. We note here that the fluorescence lifetime distribution center, width, and fractional intensity parameters were very similar to those reported earlier (1618). The most significant difference noted between the earlier and this global-linked data set was an approximate $0.1 \mathrm{~ns}$ change in the lifetime values for each species. We note that the linear relationship between $F_{\mathrm{m}}^{\prime} / F_{\mathrm{m}}$ and $f_{2}$ was very similar between the WT barley and the barley mutant clof 104, with both being slightly different from those for spinach. The intercept value in spinach was lower $(\sim 20 \%)$ than in either the barley WT or clof104.

It is clear from a comparison of these results on the lifetime of Chl $a$ fluorescence (Figure 5 and Table 1) with those on 
Table 1: Resolved Global Parameters ${ }^{a}$ from Analysis of Fluorescence Lifetime Data Constrained by Linking $f_{2}$, the Short-Lifetime Fractional Intensity, to the Observed Maximal Fluorescence Intensity with a Linear Model ${ }^{b}$

\begin{tabular}{|c|c|c|c|c|c|c|}
\hline & \multicolumn{6}{|c|}{ Linking Equation: $f_{2}=$ Slope $\times\left(F_{m}^{\prime} / F_{\mathrm{m}}\right)+$ Intercept } \\
\hline & slope $(p)$ & $\tau_{1}(\mathrm{~ns})\left(w_{1}(\mathrm{~ns})\right)$ & intercept $(p)$ & $\tau_{2}(\mathrm{~ns})\left(w_{2}(\mathrm{~ns})\right)$ & $r^{2}$ & $\chi^{2}$ \\
\hline spinach & $-1.1658(\leq 0.001)$ & $1.819(0.397)$ & $1.1549(\leq 0.001)$ & $0.456(0.305)$ & 0.9999 & 2.578 \\
\hline WT & $-1.2557(\leq 0.001)$ & $1.629(0.509)$ & $1.4234(\leq 0.001)$ & $0.495(0.756)$ & 0.9999 & 0.862 \\
\hline clof 104 & $-1.2506(\leq 0.001)$ & $1.588(0.820)$ & $1.4515(\leq 0.001)$ & $0.587(0.943)$ & 0.9999 & 0.523 \\
\hline
\end{tabular}

${ }^{a}$ All phase and modulation data fits (phase error $=1^{\circ}$; modulation error $=0.020$ ) were constrained to a bimodal Lorentzian distribution mode where the distribution centers $\left(\tau_{x}\right)$ and widths $\left(\omega_{x}\right)$ were linked across all data files. For each thylakoid source, the fractional intensity $\left(f_{x}\right)$ was linked through the linear equation and subsequently analyzed for the best fit to the lifetime data resolving both the lifetime parameters and the linking equation parameters. ${ }^{b}$ The resolved lifetime, slope, and intercept values are reported from fluorescence studies of thylakoids from spinach $(n=9)$, wild-type barley (WT, $n=15$ ), and the chlorina f104 mutant of barley (clof104, $n=13$ ). See Gilmore et al. (16, 17) for a full summary of the unlinked fluorescence lifetime parameters and statistical analysis of the fluorescence lifetime data. The $p$ values denote the probability for the null hypothesis of the slope or the intercept; $r^{2}$ is the coefficient of determination; $n$ is the number of samples.

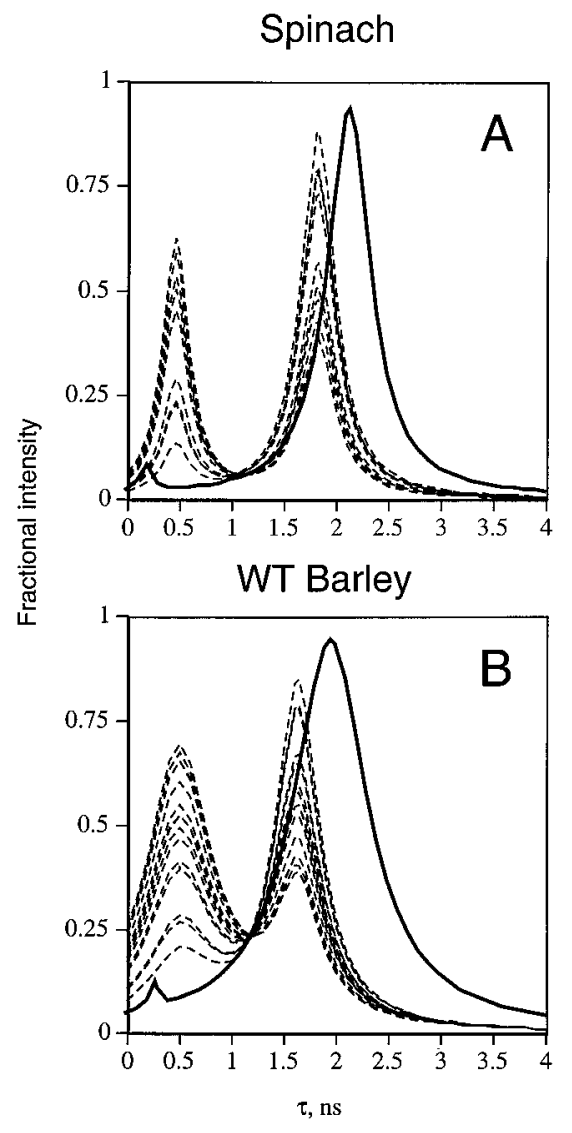

FIGURE 5: Fluorescence lifetime distributions of chlorophyll $a$ in thylakoids from spinach (panel A) and WT barley (panel B). Dashed lines represent the chlorophyll $a$ fluorescence lifetime distributions, measured at different dithiothreitol (DTT) concentrations (that changed the amounts of $\mathrm{Z}+\mathrm{A})$, under conditions when the $\mathrm{pH}$ gradient was created by ATP hydrolysis. Note that the short $(0.5$ ns) lifetime of the fluorescence component was found to decrease with increasing [DTT]. Solid lines represent the chlorophyll $a$ fluorescence lifetime distribution, measured under the condition when the $\mathrm{pH}$ gradient was dissipated by $2 \mu \mathrm{M}$ nigericin; the same curves were obtained at different [DTT]. Three milliliters of reaction mixture in all cases contained buffer C, thylakoids (7.5 $\mu \mathrm{M} \mathrm{Chl} a$ $+b)$, and $10 \mu \mathrm{M}$ DCMU.

fluorescence intensities (Figure 3) that, at high [DTT] (low $[\mathrm{Z}+\mathrm{A}]$ ), high $F_{\mathrm{m}}^{\prime} / F_{\mathrm{m}}$ (low nonphotochemical quenching) is correlated with the presence of a smaller fraction $\left(f_{2}\right)$ of the $\sim 0.5$ ns lifetime component and a higher fraction $\left(f_{1}\right)$ of the $\sim 2$ ns lifetime component. On the other hand, at low [DTT] (high $[\mathrm{Z}+\mathrm{A}]$ ), low $F_{\mathrm{m}}^{\prime} / F_{\mathrm{m}}$ (high nonphotochemical quenching) is correlated with the presence of a higher fraction $\left(f_{2}\right)$ of the $0.5 \mathrm{~ns}$ lifetime component and a lower fraction $\left(f_{1}\right)$ of the 2 ns lifetime component. Thus, the presence of the fast component $\left(c_{2}\right)$ with a lifetime of fluorescence of about $0.5 \mathrm{~ns}$ is correlated with the presence of Z. Figure 6 shows the dependence of the fraction $f_{2}$ of the component $c_{2}$ on the concentration of $\mathrm{Z}$ (panels A and D), of A (panels B and $\mathrm{E}$ ), and of $\mathrm{Z}+\mathrm{A}$ (panels $\mathrm{C}$ and $\mathrm{F}$ ) in spinach (panels A, B, and C) and barley WT (panels D, E, and F) thylakoids. Data in panels A and D are suggestive of a saturation behavior of $f_{2}$ with increasing concentrations of $Z$; the same result is observed in panels $\mathrm{C}$ and $\mathrm{F}$ for $\mathrm{Z}+\mathrm{A}$. This suggests the presence of a limited number of binding sites for $\mathrm{Z}$ or A. It appears that the short lifetime component $c_{2}$ is due to the binding of the fluorescence quencher(s) $\mathrm{Z}$ and $\mathrm{A}$.

Correlation between Chl a Fluorescence Lifetime and Intensity Measurements. Figure 7 (closed symbols) shows the correlation between the Chl $a$ fluorescence lifetime and amplitude measurements for spinach (panels A, C, and E) and barley WT (B, D, and F) when the $\mathrm{pH}$ gradient was created by ATPase only. Fluorescence intensities, measured by PAM, are reported as both $F_{\mathrm{m}}^{\prime} / F_{\mathrm{m}}$ (panel A for spinach and panel B for WT barley) and the commonly used "nonphotochemical quenching" coefficient (or NPQ) $\left(F_{\mathrm{m}}-\right.$ $\left.F^{\prime}{ }_{\mathrm{m}}\right) / F_{\mathrm{m}}^{\prime}$ (panels $\mathrm{C}$ and $\mathrm{E}$ for spinach and panels $\mathrm{D}$ and $\mathrm{F}$ for barley). Panels A and B plot $f_{2}$ as a function of $F_{\mathrm{m}}^{\prime} / F_{\mathrm{m}}$; $f_{2}$ is a linear function of $F^{\prime}{ }_{\mathrm{m}} / F_{\mathrm{m}}$ (see also Table 1). Panels $\mathrm{C}$ and $\mathrm{D}$ are plots of the fraction of the $0.5 \mathrm{~ns}$ component $\left(f_{2}\right.$ values) against $\left(F_{\mathrm{m}}-F_{\mathrm{m}}^{\prime}\right) / F_{\mathrm{m}}^{\prime}$ (equivalent to $F_{\mathrm{m}} / F_{\mathrm{m}}^{\prime}-1$ in the figure), obtained when $\Delta \mathrm{pH}$ was induced by the addition of ATP; this dependence is, however, curvilinear. Panels E and $\mathrm{F}$ are for plots of $\left(\langle\tau\rangle^{\prime} /\langle\tau\rangle\right)-1$ as a function of $\left(F_{\mathrm{m}}-\right.$ $\left.F_{\mathrm{m}}^{\prime}\right) / F_{\mathrm{m}}^{\prime}$ values, where $\langle\tau\rangle^{\prime}$ and $\langle\tau\rangle$ are the approximated average lifetimes of Chl $a$ fluorescence $\left[\langle\tau\rangle=f_{1} \tau_{1}+f_{2} \tau_{2}\right]$ at $F^{\prime}{ }_{\mathrm{m}}$ and $F_{\mathrm{m}}$, respectively. Although the $\langle\tau\rangle$ and $\langle\tau\rangle^{\prime}$ parameters do not account for differences in the distribution width or shape that can substantially alter the integrated average lifetime, they still serve in these linked analyses as quantitative predictors of the average lifetimes and of $F_{\mathrm{m}}$ and $F_{\mathrm{m}}^{\prime}$. Clearly, an almost linear relationship between these fluorescence lifetime and intensity parameters is observed. The observed relationships in panels A (and B) and E (and F) allow us to predict the lifetime of $\mathrm{Chl} a$ fluorescence and the fractions of the fast component $\left(f_{2}\right)$ from fluorescence intensities $\left(F_{\mathrm{m}}^{\prime} / F_{\mathrm{m}}\right)$ measured by PAM. As an example of the application of this idea, we calculated values (see Table 1 and the legend of Figure 7 for details) for $f_{2}$ and for $\left(\langle\tau\rangle^{\prime} \mid\right.$ $\langle\tau\rangle)-1$ from $F^{\prime}{ }_{\mathrm{m}}$ and $F_{\mathrm{m}}$ measurements, under conditions when $\Delta \mathrm{pH}$ was created by light (see open symbols in Figure 

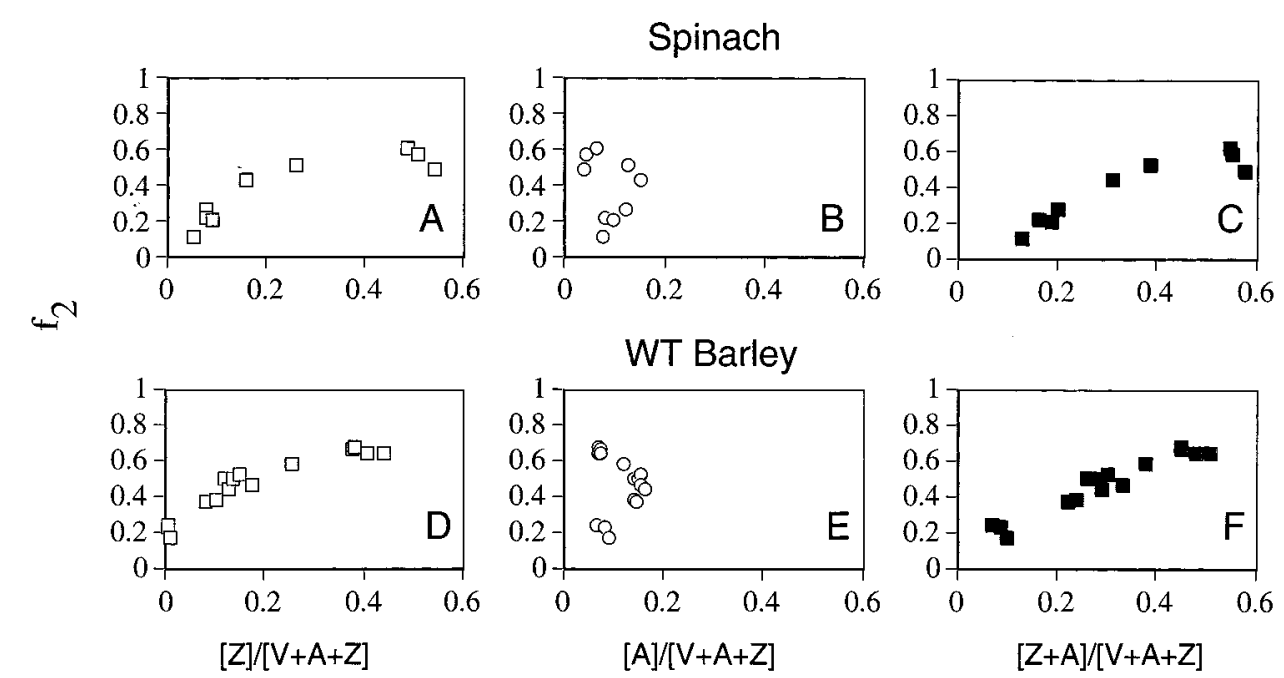

FIGURE 6: Relationship between the fractional intensity, $f_{2}$, of the $c_{2}$ lifetime component $(\sim 0.5 \mathrm{~ns})$ and the xanthophyll cycle pigments zeaxanthin (Z, open squares), antheraxanthin (A, open circles), and their sum (Z+ A, closed squares) in spinach (panels $A, B$, and $C)$ and WT barley (panels D, E, and F) thylakoids.

7). Since $f_{2}$ is linearly related to $F_{\mathrm{m}}^{\prime} / F_{\mathrm{m}}$, which decreases in proportion to increasing $[\mathrm{Z}+\mathrm{A}]$ and decreasing intrathylakoid $\mathrm{pH}$, changes in $F_{\mathrm{m}}^{\prime} / F_{\mathrm{m}}$ can be used as a direct monitor of the fluorescence lifetimes, intrathylakoid $\mathrm{pH}$, and $[\mathrm{Z}+\mathrm{A}]$.

\section{DISCUSSION}

Xanthophyll Cycle Quenching Scheme. Several qualitative models for the combined effects of $\Delta \mathrm{pH}$ and the pigments of the xanthophyll cycle are available in the literature (see, e.g., refs 1,4 , and 7). The effects of both the xanthophyll cycle pigments and $\Delta \mathrm{pH}$ on the $\mathrm{Chl} a$ fluorescence lifetimes and intensities, obtained in this paper, can be explained by a scheme shown in Figure 8. According to this scheme, light-induced electron transport or ATPase acidifies the intrathylakoid space. This acidification (see Figure 2), which can be reversed by uncouplers, has a dual synergistic role. First (see bottom middle of Figure 8), it activates the violaxanthin deepoxidase, with a $\mathrm{p} K$ of about 5.2, converting violaxanthin $(\mathrm{V})$ to antheraxanthin $(\mathrm{A})$ and then to zeaxanthin (Z) (34), and second (see top middle of Figure 8), it leads to protonation of some carboxyl groups, with a $\mathrm{p} K$ of about 4.5 , of the inner core of PSII, perhaps in CP26 and CP29 antenna complexes $(9,35,36)$. Härtel et al. (37) showed that CP24 expression lags that of CP29 and of NPQ in the greening process of barley and therefore $\mathrm{CP} 24$ may not be necessary for induction of the major NPQ component. Further, Pesaresi et al. (38) have recently shown that a single point mutation on the glutamate residue 166 to glutamine (E166Q) in CP29 prevents binding of dicyclohexylcarbodiimide to this complex in vitro. Hence, it is most likely that this is the protonatable glutamyl residue that is directly involved in the protonation steps required for induction of xanthophyll cycle-dependent energy dissipation. This protonation of the $\mathrm{CP}(\mathrm{s})$ is suggested to cause an activation of a binding site for either $\mathrm{Z}$ or $\mathrm{A}$, possibly via some conformational changes. The binding of $\mathrm{Z}$ or $\mathrm{A}$ is then suggested to cause a switching of PSII units to a state with an increased rate constant of heat dissipation (16-18), leading to the quenching of $\mathrm{Chl} a$ fluorescence (a "dimmer switch" effect), as measured by the pulse amplitude modula- tion fluorometer (Figures 3 and 4 ) or by multifrequency phase fluorometry (Figures 5 and 6). We note that the sulfhydryl reagent dithiothreitol (DTT) inhibits deepoxidation (34) without inhibiting either the light-driven or ATPase-mediated proton pumps. By varying the concentration of DTT, we were able to obtain different concentrations of $\mathrm{Z}$ and $\mathrm{A}$ (see Figure 1). Further, the uncouplers do not alter the $[\mathrm{Z}+\mathrm{A}]$ in isolated thylakoid membranes unless $\mathrm{NAD}(\mathrm{P}) \mathrm{H}$ is added to activate the epoxidase enzyme (see refs 28 and 39).

Kinetic Model for the Analysis of the $\mathrm{pH}$ and Xanthophyll Cycle Concentration Dependence of PSII Fluorescence. In the current model, only $\mathrm{Z}$ and $\mathrm{A}$ are considered as quenchers, although in other systems (e.g., Chlamydomonas), other molecules (e.g., lutein; see ref 40) may also be considered without affecting the kinetic model presented here. Although a large number of $\mathrm{Z}$ and $\mathrm{A}$ molecules may be present in the total xanthophyll pool, only one molecule per PSII is suggested, for simplicity, to be involved in the energy dissipation mechanism. In our model, only bound $\mathrm{Z}$ and $\mathrm{A}$ can quench Chl $a$ fluorescence because (a) no evidence exists for collisional quenching in the present system, (b) the most likely mechanism of quenching is the electron-exchange Dexter mechanism (see ref 41), and (c) only $\mathrm{Z}$ and A, not $\mathrm{V}$, can quench Chl $a$ fluorescence, suggesting a specific binding niche. In our concept, each $\mathrm{Z}$ and $\mathrm{A}$ molecule has a given average probability to fill the activated binding niche and quench Chl $a$ fluorescence.

To quantitatively incorporate the effects of the $\mathrm{pH}$ on the xanthophyll cycle-dependent $\mathrm{Chl} a$ fluorescence quenching, we assume that protonation of carboxyl moieties on the lumenal side of the PSII inner core antenna proteins (primarily CP29) is necessary for the reversible activation of the binding site for $\mathrm{Z}$ ( or A). Here we note that there may be several carboxyl moieties (perhaps more than four, assuming two for each CP26 and CP29 unit per PSII) involved in the $\mathrm{pH}$ activation for each binding site. As implied from the work in ref 38, it may be only CP29 that may have to be considered further. But, we must keep other options open. We may envision a scenario where protonation of the carboxyl groups releases counterions (probably divalent), thus changing the charged properties of these functional 

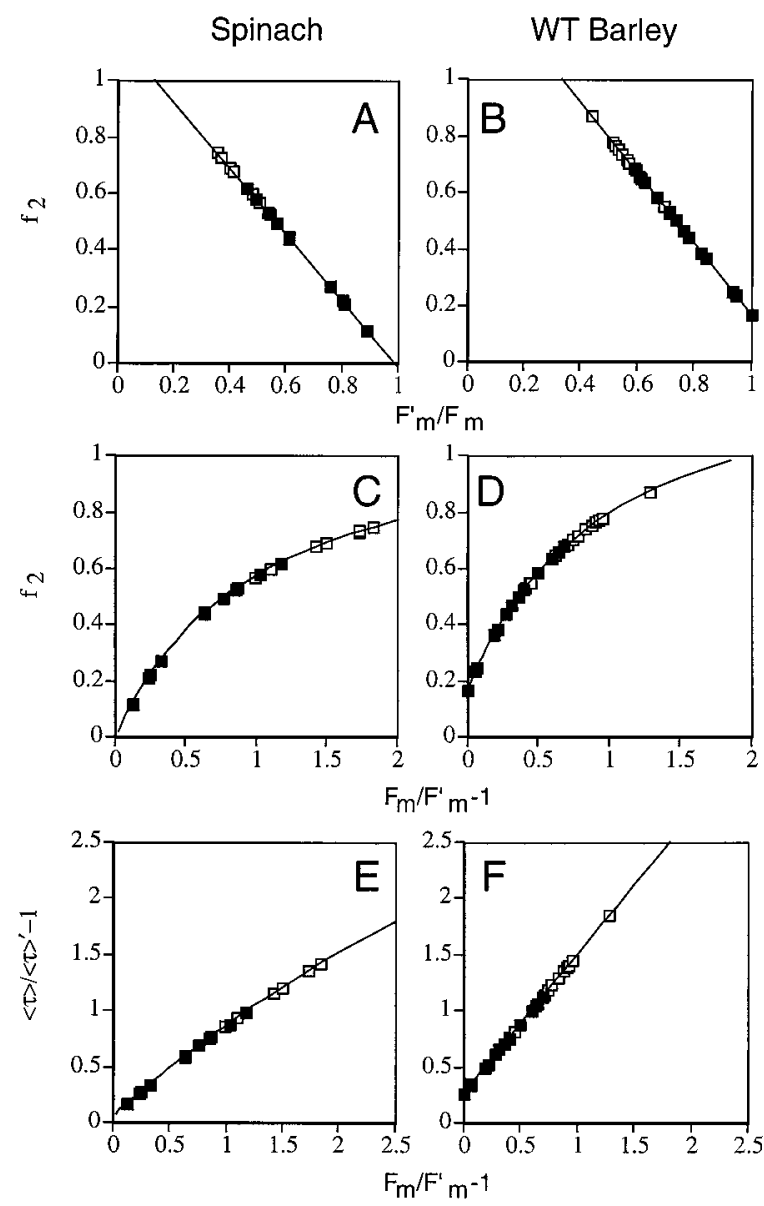

FIGURE 7: Correlation between chlorophyll $a$ fluorescence lifetime and steady-state parameters in spinach (panels A, C, and E) and WT barley (panels B, D, and F) thylakoids. Panels A and B show the dependence of $f_{2}$ (fractional intensity of the 0.5 ns fluorescence component) on $F_{\mathrm{m}}^{\prime} / F_{\mathrm{m}}$ (where $F_{\mathrm{m}}^{\prime}$ and $F_{\mathrm{m}}$ are the maximum fluorescence yields obtained in the presence and absence of the $\mathrm{pH}$ gradient). Panels $\mathrm{C}$ and $\mathrm{D}$ show the dependence of $f_{2}$ on nonphotochemical quenching $\left[\left(F_{\mathrm{m}}-F_{\mathrm{m}}^{\prime}\right) / F_{\mathrm{m}}^{\prime}\right]$, and panels $\mathrm{E}$ and $\mathrm{F}$ show the dependence of $\left(\langle\tau\rangle-\left\langle\tau^{\prime}\right\rangle\right) /\left\langle\tau^{\prime}\right\rangle$ (where $\left\langle\tau^{\prime}\right\rangle$ and $\langle\tau\rangle$ are the average lifetimes of chlorophyll $a$ fluorescence in the presence and absence of the $\mathrm{pH}$ gradient) on nonphotochemical quenching $\left[\left(F_{\mathrm{m}}-F_{\mathrm{m}}^{\prime}\right) / F_{\mathrm{m}}^{\prime}\right.$, labeled as $F_{\mathrm{m}} / F_{\mathrm{m}}^{\prime}-1$ in the figure $]$. Closed symbols represent experimental data for samples when the $\mathrm{pH}$ gradient was made by ATPase; open symbols represent calculated data for samples when the $\mathrm{pH}$ gradient was made by light (for details, see text).

groups and hence their structural interaction with other neighboring functional amino acid groups, lipid headgroups, or proteins. We speculate that a dynamic refolding and/or rearrangement within and/or between $\mathrm{CP}$ proteins results in the exposure of the binding domain for $\mathrm{Z}$ and $\mathrm{A}$.

To summarize the protonation step(s), we use the following simple scheme:

$$
\mathrm{H}^{+}+\underset{(\mathrm{W})}{\mathrm{CP}-\mathrm{COO}^{-}} \stackrel{\mathrm{pK}}{\rightleftharpoons} \mathrm{CP}-\mathrm{COOH}
$$

where $\mathrm{W}$ in parentheses denotes the binding site for $\mathrm{Z}$ and/ or $\mathrm{A}$ and $\mathrm{X}$ denotes the protonated (activated) binding site that has a high binding affinity for $\mathrm{Z}$ (or A). We include both $\mathrm{Z}$ and $\mathrm{A}$ as quenchers of $\mathrm{Chl} a$ fluorescence, as discussed earlier under Results. The $\mathrm{pH}$ dependence of relative populations of these two states of the binding site is given by the Henderson-Hasselbach equation:

$$
\mathrm{pH}=\mathrm{p} K+\log \frac{[\mathrm{W}]}{[\mathrm{X}]}
$$

We propose here that all the $\mathrm{Z}$ and $\mathrm{A}$ molecules present in the PSII unit compete for the binding site. For simplicity, we suggest that each molecule may bind with equal probability. A similar approach can be used even if $\mathrm{Z}$ and $\mathrm{A}$ had different binding efficiencies. The $\mathrm{Z}$ and $\mathrm{A}$ molecules interact in a reversible manner with this binding site. Therefore, the binding scheme in eq 3 is characterized by the equilibrium association constant $K_{\mathrm{a}}$ (here for simplicity we show only Z):

$$
\mathrm{Z}+\underset{(\mathrm{X})}{\mathrm{CP}-\mathrm{COOH}} \stackrel{K_{\mathrm{a}}}{\mathrm{Z}}-\mathrm{CP}-\mathrm{COOH}
$$

where $\mathrm{Y}$ in parentheses denotes the protonated (activated) binding site with $\mathrm{Z}$ present.

The equilibrium binding (association) constant $K_{\mathrm{a}}$ is given by the equation:

$$
K_{\mathrm{a}}=\frac{[\mathrm{Y}]}{[\mathrm{X}][\mathrm{Z}]}
$$

Combining eqs 1 and 3 gives the reaction scheme:

$$
\begin{aligned}
& \mathrm{H}^{+}+\underset{(\mathrm{W})}{\mathrm{CP}-\mathrm{COO}^{-} \stackrel{\mathrm{pK}}{\rightleftharpoons} \mathrm{Z}}+\underset{\left(\begin{array}{l}
\mathrm{CP} \\
(\mathrm{XOOH}
\end{array}\right.}{\stackrel{K_{\mathrm{a}}}{\rightleftharpoons}} \\
& \begin{array}{c}
\mathrm{CP}-\mathrm{COOH} \\
(\mathrm{Y})
\end{array} \\
& \left(\tau_{\mathrm{f}}=1.6-2.0 \mathrm{~ns}\right) \\
& =0.4-0.5 \mathrm{~ns})
\end{aligned}
$$

The Chl $a$ fluorescence lifetimes $\left(\tau_{\mathrm{f}}\right)$ listed above are suggested ranges of values for the species ( $\mathrm{X}$ and $\mathrm{Y}$ ) in spinach. We note that the above-described protonation event, related to the activation of the binding site (see Figure 8), is not the same as that which leads to the change in lifetime of fluorescence from 2.2 to $1.8 \mathrm{~ns}$ (see Figure 7 for spinach). This may have a different origin, such as conformational changes.

Equations 2 and 4 together with the balanced equation for the binding site

$$
[\mathrm{W}]+[\mathrm{X}]+[\mathrm{Y}]=[\mathrm{Tot}]
$$

yield the equation for the fraction of binding sites occupied by $\mathrm{Z}$ at steady state:

$$
\frac{[\mathrm{Y}]}{[\mathrm{Tot}]}=\frac{[\mathrm{Y}]}{[\mathrm{W}]+[\mathrm{X}]+[\mathrm{Y}]}=\frac{[\mathrm{Z}] K_{\mathrm{a}}^{\mathrm{app}}}{1+[\mathrm{Z}] K_{\mathrm{a}}^{\mathrm{app}}}
$$

where the apparent binding constant

$$
K_{\mathrm{a}}^{\mathrm{app}}=\frac{K_{\mathrm{a}}}{1+10^{\mathrm{pH}-\mathrm{p} K}}
$$

It is obvious from the right side of the eq 7 that the dependence of the fraction of occupied (Y) binding sites is described by a simple hyperbolic equation. On the other hand, the apparent binding constant $\left(K_{\mathrm{a}}^{\mathrm{app}}\right)$ increases drastically as the $\mathrm{pH}$ falls below $\mathrm{p} K$ (eq 8). 


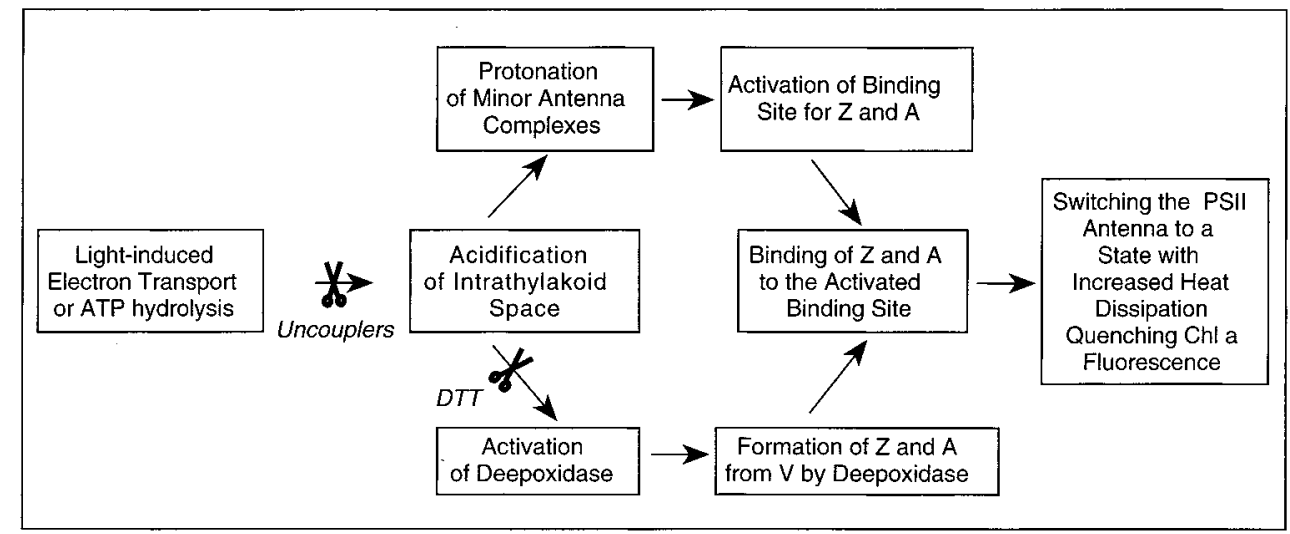

FIGURE 8: A model, consistent with our data, of how the intrathylakoid $\mathrm{pH}$ and xanthophyll cycle pigments lead to quenching of PSII chlorophyll $a$ fluorescence yield (also, see refs 1,4 , and 7).

Equation 7 can also be written using $\mathrm{p} K$ and $K_{\mathrm{a}}$ as

$$
\frac{[\mathrm{Y}]}{[\mathrm{Tot}]}=\frac{K_{\mathrm{a}}[\mathrm{Z}] 10^{\mathrm{p} K-\mathrm{pH}}}{1+10^{\mathrm{p} K-\mathrm{pH}}\left(1+K_{\mathrm{a}}[\mathrm{Z}]\right)}
$$

We use eq 9 to analyze and fit our experimental data. We suggest that the introduced fractions (W), (X), and (Y) represent different states of the PSII units that have different respective fluorescent yields and lifetimes, as outlined in eq 5. We identify the fractions $[\mathrm{Y}] /[\mathrm{Tot}]=f_{2}$ and $[\mathrm{W}+$ $\mathrm{X}] /[$ Tot $]=f_{1}$ with the fractions of PSII units in the short $\left(\tau_{\mathrm{f}}\right.$ $\approx 0.5 \mathrm{~ns}$ ) and long $\left(\tau_{\mathrm{f}} \approx 1.9 \mathrm{~ns}\right)$ Chl $a$ fluorescence lifetime states, respectively. We emphasize that we have considered here the simplest case when only a single binding site for the quencher is present per PSII. If, however, there is more than one interacting binding site, eq 9 should be modified accordingly.

Relationship between the PSII Fractional Intensity, the Relative Zeaxanthin and Antheraxanthin Concentrations, and the Intrathylakoid $\mathrm{pH}$. A major use of the model discussed above is in quantitatively explaining the combined data on the lifetime of the fluorescence, concentrations of the quenchers, and the intrathylakoid $\mathrm{pH}$. The model allows us to analyze and discuss the $\mathrm{pH}$ and xanthophyll cycledependent changes in the PSII fluorescence yield with respect to $\mathrm{p} K$ and $K_{\mathrm{a}}$ values. Panels $\mathrm{A}-\mathrm{C}$ of Figure 9 show plots of the fractional intensity of the $0.5 \mathrm{~ns}$ fluorescence component $\left(f_{2}\right)$ against [Z] per PSII, under three intrathylakoid $\mathrm{pH}$ levels. The open squares represent the experimental points when the $\mathrm{pH}$ gradient is obtained by illuminating the samples with light, the closed squares when the $\mathrm{pH}$ gradient is obtained by the ATPase, and the closed circles when the $\mathrm{pH}$ gradient is dissipated by nigericin. Panels $\mathrm{D}-\mathrm{F}$ of Figure 9 show plots of $f_{2}$ versus [Z] $+x$ [A] per PSII, where $x$ is about 1 , ranging from 0.83 to 1.34 . For each $\mathrm{pH}$ condition in Figure 9 (panels D-F), the solid lines represent the model mean, while the dotted lines denote the $( \pm)$ standard deviation range of the $K_{\mathrm{a}}$ values. The values of $\mathrm{pH}$ were taken from measurements with 9-aminoacridine (see Figure 2). The $\mathrm{p} K$ was assumed to be 4.5 . Then, the experimental data points were fitted by eq 9 to find $K_{\mathrm{a}}$. Panels $\mathrm{G}-\mathrm{I}$ of Figure 9 show that when only $[\mathrm{Z}]$ is considered a quencher of fluorescence (open diamonds), then the calculated $K_{\mathrm{a}}$ values for each data point show large differences in all three types of materials; note especially that in Figure 9 (panel H,
WT barley, and panel I, mutant barley clof104) there is a very large systematic deviation, reaching values of $\sim 100$. Since $K_{\mathrm{a}}$ must be a constant for each sample point independent of the $\mathrm{pH}$ and $[\mathrm{Z}+\mathrm{A}]$, this result suggests that another parameter is needed to fit the curves correctly. As discussed earlier, [A] is also a possible quencher of Chl $a$ fluorescence (see Figure 4). Thus, we fitted the experimental data points by using eq 9 but replacing $[\mathrm{Z}]$ with $[\mathrm{Z}]+x[\mathrm{~A}]$ (see filled diamonds in Figure 9G-I). The newly calculated $K_{\mathrm{a}}$ values were found to fall in a narrow range. As shown in panels $\mathrm{J}-\mathrm{L}$ of Figure 9, both the $F$-test and $r^{2}$ values for the model indicate that the best fitting relative value for the fraction of the total pool of $[\mathrm{A}]=x$ is about equal to that of $[\mathrm{Z}]$, i.e., supporting the conclusion that $\mathrm{A}$ is a quencher (42) and $x \approx$ 1.

Comparison of the Intrathylakoid $\mathrm{pH}$ Calculated from the Model to That Measured by Uptake of 9-Aminoacridine. In the above discussion, we had used the measured values of the $\mathrm{pH}$ gradient in calculating $K_{\mathrm{a}}$. Now, we show below that even the value of $\mathrm{pH}$ can be estimated by fitting eq 9 with the experimental data. Figure 2 shows a comparison of these predictions (open bars) of the $\mathrm{pH}$ with those measured by 9 -aminoacridine fluorescence quenching (shaded bars). The best fitting $\mathrm{pH}$ predictions were obtained by using the iterative fitting routine. The values from both the model and quenching of the 9-aminoacridine fluorescence yield closely parallel each other. The lowest intrathylakoid $\mathrm{pH}$ of $\approx 4.5$ was measured under the light-saturating conditions (see "Light" in Figure 2), and the next lowest $\mathrm{pH}$ of $\approx 5.3$ was obtained under the ATPase-mediated conditions (ATPase). Since there is no dependence of $f_{2}$ on $[\mathrm{Z}+\mathrm{A}]$ under uncoupled conditions, the model could not provide any insight here.

Biophysical and Photophysical Aspects Concerning the Roles of Antheraxanthin and Zeaxanthin. We can explain the quenching of $\mathrm{Chl} a$ fluorescence by $\mathrm{Z}$ and A, but not by $\mathrm{V}$, by assuming that only $\mathrm{Z}$ and $\mathrm{A}$ can accept singlet excitedstate energy from Chl $a$ and subsequently dissipate this energy as heat $(8,41)$. In this theory, the predicted energy level of violaxanthin is above, whereas that of antheraxanthin and zeaxanthin is below, that of the first excited singlet state of Chl $a$. The calculated lifetime of the singlet excited state of the carotenoid after accepting an exciton from Chl $a$ is predicted to be $\tau=9 \mathrm{ps}$ for zeaxanthin and $\tau=14.4 \mathrm{ps}$ for antheraxanthin (41); however, this has not yet been measured. 
Spinach
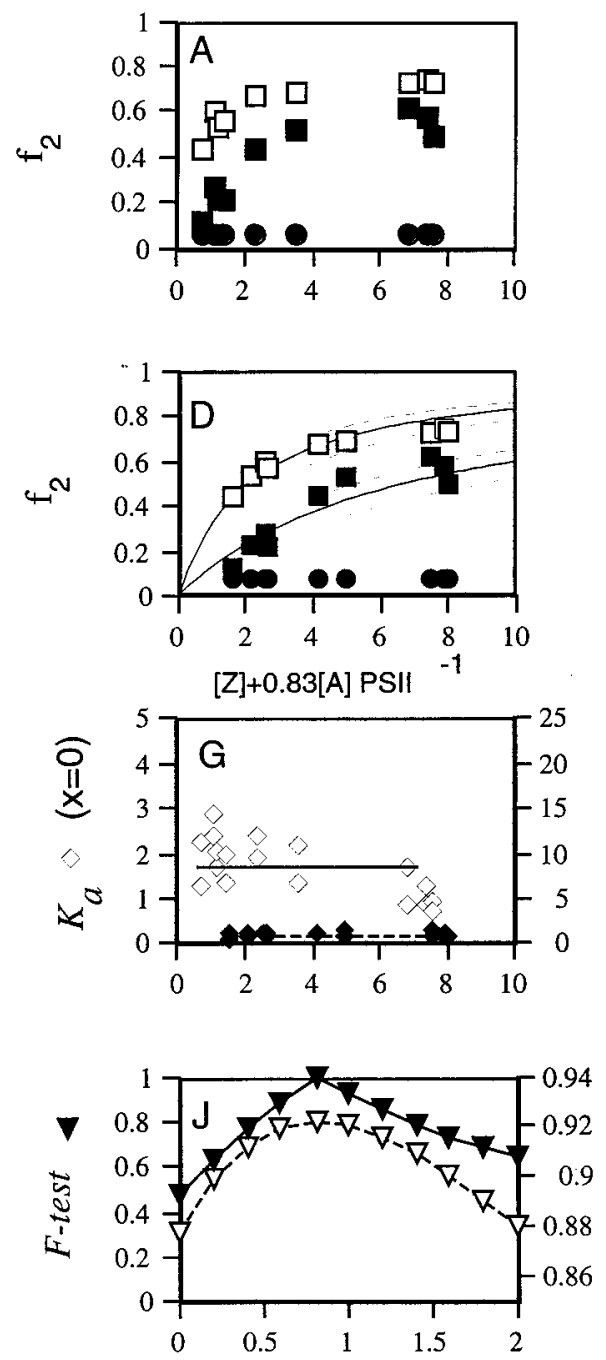

WT Barley
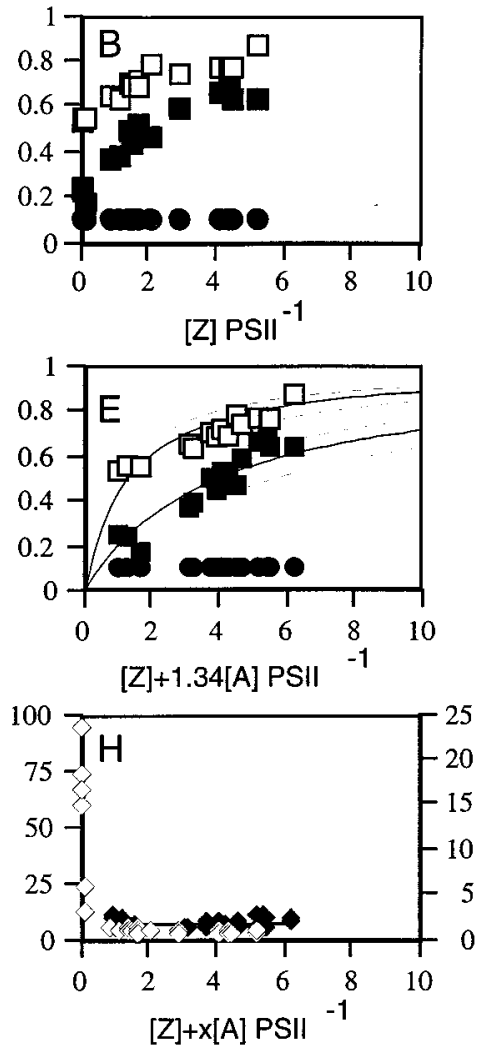

Barley clof104
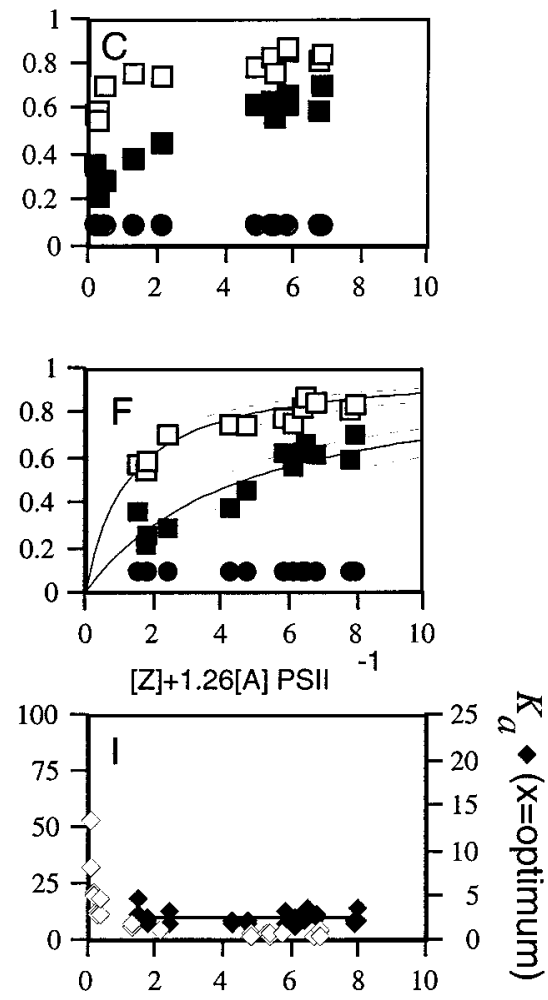

FIGURE 9: Top row: fractional intensity, $f_{2}$, of the $0.5 \mathrm{~ns}$ component as a function of the concentration of zeaxanthin (Z) per PSII under conditions when the $\mathrm{pH}$ gradient was made by light (open squares) or by ATPase (closed squares) and when the pH gradient was dissipated by nigericin (closed circles) in thylakoids from spinach, WT barley, and the barley mutant clof104. Second row: same as the first row except that $f_{2}$ is plotted as a function of [Z] $+x[\mathrm{~A}]$. Third row: association constant, $K_{\mathrm{a}}$ as a function of [Z] $+x[\mathrm{~A}]$ for $x=0$ (open diamonds) and for $x=$ optimal value (closed diamonds). Fourth row: the $F$-test and the $r^{2}$ for different values of $x$.

Frank et al. (41) have suggested a Dexter-based exchange mechanism which requires molecular orbital overlap and hence a very close physical proximity. We suggest that bound $\mathrm{Z}$ and $\mathrm{A}$ may indeed be in close proximity to Chls in the antenna complex; like the deepoxidation and epoxidation reactions (see ref 43), this binding is probably stereospecific (34) for the $\mathrm{Z}$ and $\mathrm{A}$ and presumably facilitated by a $\mathrm{pH}-$ activated step (Figure 8). An alternate hypothesis to the idea of Frank et al. is that $\mathrm{Z}$ and A may trigger structural or conformational changes around $\mathrm{Chl}$ molecules in the vicinity of the binding site, indirectly increasing the internal conversion processes of the Chls and the entire PSII unit (4).

Concluding Remarks. Using parallel time-resolved and pulse-amplitude modulation (PAM) fluorometry, we have studied the influence of the intrathylakoid $\mathrm{pH}$ (measured by 9-aminoacridine uptake) and the xanthophyll cycle carotenoids (measured by HPLC) on PSII Chl $a$ fluorescence yield in thylakoids of three different species. To quantitatively explain the combined effects of $\mathrm{pH}$ and of zeaxanthin plus antheraxanthin concentrations on time-resolved (Figures
5, 6, and 9) and steady-state (Figure 4) Chl $a$ fluorescence, we have presented here a new quantitative model which assumes that (a) there exists a specific binding site for a few (for simplicity, one) zeaxanthin (or antheraxanthin) molecules among or in the inner antenna of PSII, (b) this binding site is activated by a low intrathylakoid $\mathrm{pH}$ that increases the affinity for zeaxanthin (or antheraxanthin), and (c) this binding effectively "switches" the fluorescence lifetime distribution of the PSII unit to a state with a decreased fluorescence lifetime and emission intensity (the idea of a dimmer switch). The model explains (a) changes in the relative fractional intensities of the $\sim 0.5 \mathrm{~ns}$ fluorescence component as a function of both zeaxanthin (and antheraxanthin) concentration and intrathylakoid $\mathrm{pH}$, (b) the dependence of the ratio of $F_{\mathrm{m}}^{\prime} / F_{\mathrm{m}}$ on the fraction of the $0.5 \mathrm{~ns}$ fluorescence lifetime component, and (c) the dependence of the ratio $F_{\mathrm{m}}^{\prime} / F_{\mathrm{m}}$ on both the concentration of zeaxanthin (and antheraxanthin) and intrathylakoid $\mathrm{pH}$. Finally, and importantly (see Figures 7 and 9), the correlation between the measurements on the lifetime of fluorescence and amplitude, 
statistically supported here for three higher plant species, allows one to predict the changes of [Z] both from the lifetime of fluorescence measurements and from the amplitude measurements with pulse amplitude fluorometers (PAM) that are available commercially.

\section{ACKNOWLEDGMENT}

We are indebted to Drs. Olle E. Björkman, Barbara Demmig-Adams, and William Adams III, their laboratory staff, and graduate students for the use of HPLC facilities and Ms. Purna Lakhia for her help in growing the plants and for laboratory assistance.

\section{REFERENCES}

1. Horton, P., Ruban A. V., and Walters, R. G. (1996) Annu. Rev. Plant Physiol. Plant Mol. Biol. 47, 655-684.

2. Björkman, O., and Demmig-Adams, B. (1994) Ecol. Stud. 100, 17-47.

3. Long, S. P., Humphries, S., and Falkowski, P. G. (1994) Annu. Rev. Plant Physiol. Plant Mol. Biol. 45, 633-662.

4. Demmig-Adams, B., Gilmore, A. M., and Adams, W. W., III (1996) FASEB J. 10, 403-412.

5. Demmig-Adams, B., and Adams, W. W., III (1996) Trends Plant Sci. 1, 21-26.

6. Yamamoto, H. Y., and Bassi, R. (1996) in Oxygenic Photosynthesis: The Light Reactions (Ort, D. R., and Yocum, C. F., Eds.) pp 539-563, Kluwer Academic Publishers, Dordrecht, The Netherlands.

7. Gilmore, A. M. (1997) Physiol. Plant. 99, 197-209.

8. Owens, T. G. (1996) in Photosynthesis and the Environment (Baker, N. R., Ed.) pp 1-23, Kluwer Academic Press, Dordrecht, The Netherlands.

9. Green, B. R., and Durnford, D. G. (1996) Annu. Rev. Plant Physiol. Plant Mol. Biol. 47, 685-714.

10. Bassi, R., Pineau, B., Dainese, P., and Marquardt, J. (1993) Eur. J. Biochem. 212, 297-303.

11. Horton, P., and Ruban, A. V. (1992) Photosynth. Res. 34, 375385.

12. Porra, R. J., Thompson, W. A., and Kriedmann, P. E. (1989) Biochim. Biophys. Acta 975, 384-394.

13. Spencer, R. D., and Weber, G. (1970) J. Chem. Phys. 52, 1654-1663.

14. Jameson, D. M., and Hazlett, T. L. (1991) in Biophysical and Biochemical Aspects of Fluorescence Spectroscopy (Dewey, G., Ed.) pp 105-133, Plenum Press, New York.

15. Govindjee, Van de Ven, M., Cao, J., Royer, C., and Gratton, E. (1993) Photochem. Photobiol. 58, 438-445.

16. Gilmore, A. M., Hazlett, T. L., and Govindjee (1995) Proc. Natl. Acad. Sci. U.S.A. 92, 2273-2277.

17. Gilmore, A. M., Hazlett, T. L., Debrunner, P. G., and Govindjee (1996) Photosynth. Res. 48, 171-187.

18. Gilmore, A. M., Hazlett, T. L., Debrunner, P. G., and Govindjee (1996) Photochem. Photobiol. 64, 552-563.
19. Frauenfelder, H., Parak, F., and Young, R. D. (1988) Аnnu. Rev. Biophys. Biophys. Chem. 17, 451-479.

20. Gratton, E., Jameson, D. M., and Hall, R. D. (1984) Annu. Rev. Biophys. Bioeng. 13, 105-124.

21. Jahns, P., and Junge, W. (1990) Eur. J. Biochem. 193, 731736.

22. James, D. R., Liu, Y.-S., Siemiarczuk, A., Wagner, B. D., and Ware, W. R. (1988) Proc. SPIE-Int. Soc. Opt. Eng. 909, 9096.

23. Yamamoto, H. Y., Nakayama, T. O. M., and Chichester, C. O. (1962) Arch. Biochem. Biophys. 97, 168-173.

24. Hager, A. (1969) Planta 89, 224-243.

25. Yamamoto, H. Y., and Kamite, L. (1972) Biochim. Biophys. Acta 267, 538-543.

26. Gilmore, A. M., and Yamamoto, H. Y. (1992) Proc. Natl. Acad. Sci. U.S.A. 89, 1899-1903.

27. Sokolove, P. M., and Marsho, T. V. (1976) Biochim. Biophys. Acta 430, 321-326.

28. Siefermann, D., and Yamamoto, H. Y. (1975) Arch. Biochem. Biophys. 171, 70-77.

29. Duysens, L. N. M., and Sweers, H. E. (1963) in Studies on Microalgae and Photosynthetic Bacteria (Japanese Society of Plant Physiologists, Eds.) pp 353-372, University of Tokyo Press, Tokyo, Japan.

30. Horton, P., and Black, M. T. (1981) Biochim. Biophys. Acta 635, 53-62.

31. Gilmore, A. M., and Yamamoto, H. Y. (1991) J. Chromatogr. $543,137-145$.

32. Schuldiner, S., Rottenberg, H., and Avron, M. (1972) Eur. J. Biochem. 25, 64-70.

33. Pick, U., and McCarty, R. E. (1980) Methods Enzymol. 69C, 538-548.

34. Yamamoto, H. Y. (1979) Pure Appl. Chem. 51, 639-648.

35. Crofts, A. R., and Yerkes, C. T. (1994) FEBS Lett. 352, 265270.

36. Walters, R. G., Ruban, A. V., and Horton, P. (1996) Proc. Natl. Acad. Sci. U.S.A. 93, 14204-14209.

37. Härtel, H., Lokstein, H., Grimm, B., and Rank, B. (1996) Plant Physiol. 110, 471-482.

38. Pesaresi, P., Sandona, D., Giuffra, E., and Bassi, R. (1997) FEBS Lett. 402, 151-156.

39. Gilmore, A. M., Mohanty, N., and Yamamoto, H. Y. (1994) FEBS Lett. 350, 271-274.

40. Niyogi, K. K., Björkman, O., and Grossman, A. R. (1997) Proc. Natl. Acad. Sci. U.S.A. 94, 14162-14167.

41. Frank, H. A., Cua, A., Chynwat, V., Young, A., Gosztola, D., and Wasielewski, M. R. (1994) Photosynth. Res. 41, 389395.

42. Gilmore, A. M., and Yamamoto, H. Y. (1993) Photosynth. Res. 35, 67-78.

43. Bugos, R. C., Hieber, A. D., and Yamamoto, Y. (1998) J. Biol. Chem. 273, 15321-15324.

BI981384X 